Article

\title{
Comparison of Temperature Control and Temperature Difference Control for a Kaibel Dividing Wall Column
}

\author{
Xing Qian ${ }^{\circledR}$, Rui Liu, Kejin Huang *, Haisheng Chen, Yang Yuan, Liang Zhang and \\ Shaofeng Wang \\ College of Information Science and Technology, Beijing University of Chemical Technology, \\ Beijing 100029, China; qianx@mail.buct.edu.cn (X.Q.); 2017310228@mail.buct.edu.cn (R.L.); \\ chenhs@mail.buct.edu.cn (H.C.); yuanyang@mail.buct.edu.cn (Y.Y.); zhangl@mail.buct.edu.cn (L.Z.); \\ sfwang@mail.buct.edu.cn (S.W.) \\ * Correspondence: huangkj@mail.buct.edu.cn
}

Received: 13 September 2019; Accepted: 18 October 2019; Published: 21 October 2019

\begin{abstract}
A dividing wall column (DWC) effectively intensifies the distillation process with a reduced energy consumption, capital investment, and space. The three-product DWC has been investigated intensively and extensively; however, the four-product Kaibel DWC has received scarce attention. This study aimed to propose feasible control structures for the Kaibel DWC using only temperature sensors in order to promote its industrialization. Two temperature control structures, two temperature difference control structures, and two double temperature difference control structures were studied. The feasibility of the six proposed control structures was verified with a wide variety of feed disturbances. In most cases, temperature difference control was better than temperature control to maintain product purities. The dynamic performances proved that the inserted feed disturbances were handled well. These results help to promote the industrialization of the Kaibel DWC.
\end{abstract}

Keywords: dividing wall column (DWC); Kaibel column; temperature control; temperature difference control; process simulation

\section{Introduction}

In chemical industries, distillation unit operation is one of the most widely applied technology for separating liquid mixtures, but it has a high energy consumption and low energy efficiency. A dividing wall column (DWC) is a promising strategy that can considerably save on capital and operating costs. The three-product Petlyuk DWC, which has been successfully employed in chemical industries, provides a feasible method for process intensification techniques [1]. DWC contains only one distillation column integrated with a vertical dividing wall that requires a substantially decreased space, capital cost, and operating expense as compared with the traditional processes [2,3]. The three-product Petlyuk DWC is able to reduce energy usage by about 30\% [4], while the four-product Kaibel DWC can save about $40 \%$ on energy usage [5,6]. Kaibel [7] first proposed the distillation column with a vertical partition that is able to separate four pure fractions, and researchers [8] introduced this arrangement as the four-product Kaibel DWC, as shown in Figure 1. A, B, C, and D represent the four pure fractions. F stands for the feed while $S 1$ and $S 2$ indicate the upper and lower side products.

The complicated structure of a DWC, however, inevitably produces excessive interactions and highly nonlinear behaviors. These intensify the difficulty of the design and control of a DWC. Misgivings about the optimization and controllability problems impedes the industrialization of a DWC. In order to provide a way toward the industrialization of a DWC, pioneer researchers and scholars have studied 
the design and control of different DWC configurations, including the three-product Petlyuk DWC, azeotropic DWC (ADWC), extractive DWC (EDWC), and reactive DWC (RDWC).

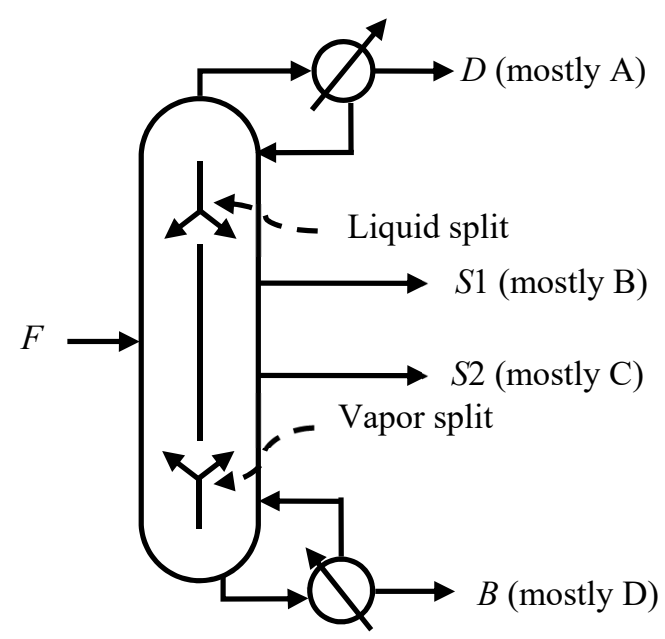

Figure 1. Kaibel dividing wall column (Kaibel DWC).

Based on the three-product Petlyuk DWC, Wolff and Skogestad [9] proposed a three-point control scheme using the reflux stream controlling the top product purity, the vapor boilup controlling the bottom product purity, and the side product stream controlling its purity. Wang and Wong [10] investigated the trade-off between the energy saving ability of the three-product Petlyuk DWC and its controllability. Ling and Luyben [11] studied a four-point control structure with an additional pairing of $\beta_{\mathrm{L}}-y_{2}$ besides the three-point control structure ( $y_{2}$ is the heavy impurity o-xylene in the overhead vapor stream at the top of the prefractionator) on the basis of the three-product Petlyuk DWC. They [12] further investigated a four-point temperature control (TC) structure and the corresponding temperature difference control (TDC) structure for the same system. Dwivedi et al. [13,14] studied feasible composition and composition/temperature cascade control schemes for both the three-product Petlyuk DWC and the four-product extended Petlyuk DWC. Fan et al. [15] and Qian et al. [16] investigated the controllability and operability of the Kaibel DWC. Various feasible control schemes were proposed, including a composition control scheme, a TC scheme, and a composition/temperature cascade control scheme. Jia et al. [17] investigated a new optimization strategy with a support vector machine strategy, as well as a particle swarm optimization method for the synthesis and design of the three-product DWC. They [18] also compared the TC and composition/temperature cascade control structures on the basis of the same system, and the results show that a pure temperature control structure is the best. Kiss and Ignat [19] and Kiss and Suszwalak [20] combined azeotropic/extractive distillation with DWC (ADWC/EDWC) for the first time and proved that ADWC/EDWC was able to save energy usage by about $20 \%$ using different systems. Le et al. [21] investigated a heterogeneous ADWC configuration that could save energy usage by about $20 \%$ compared with the original configuration when separating water and acetic acid. Luyben [22] modified the bioethanol dehydration EDWC with vapor recompression. Through a portion of vapor recompression and the introduction of auxiliary condensers, the dynamic robustness of the configuration improved a lot. Staak and Grutzner [23] aimed to close the gap between the published data for the EDWC and the industrialized EDWC. An EDWC developed and implemented by the Lonza was carried out based on simulations without pilot or mini plant experiments. This method significantly shortened the time-to-market cycle and helped save on the industrialization investment to a large extent. Delgado-Delgado et al. [24] experimentally tested the production of ethyl acetate in a RDWC and the experimentally observed results agreed with the results of simulations. Feng et al. [25] studied the energy-saving potential of a combination of a vapor recompression heat pump (VRHP) with a lower partitioned RDWC. Through integrating a preheater, the innovative VRHP-assisted RDWC configuration could reduce the energy cost by $49.86 \%$. 
Kiss and Suszwalak [26] used state-of-the-art sequential quadratic programming for the synthesis and design of a RDWC. The obtained results showed that the energy-saving ability of this RDWC is as high as $58 \%$ compared with the typical reaction and distillation process.

The main features of the Kaibel DWC are the vertical dividing wall, the liquid split above the dividing wall, and the vapor split below the dividing wall. For simulation purposes, the thermally equivalent configuration of the Kaibel DWC with the thermally coupled liquid and vapor streams between the columns are shown in Figure 2. This paper proposes two temperature control (TC1 and TC2) structures, two temperature difference control (TDC1 and TDC2) structures, and two double temperature difference control (DTDC1 and DTDC2) structures for the Kaibel DWC. Sensitivity analysis (SA) and singular value decomposition analysis (SVDA) were used for choosing reference temperatures and sensitive temperatures. As one TC loop is generally required for each split in order to stabilize the distillation operation [27], we should use at least four temperature controllers in the Kaibel DWC. TC1, TDC1, and DTDC1 employ liquid splitting in the control structures, while TC2, TDC2, and DTDC2 use vapor splitting in the control structures. The feasibility of the six proposed control structures was examined through a wide range of feed disturbances. Comparisons and discussions are made based on the dynamic performances.

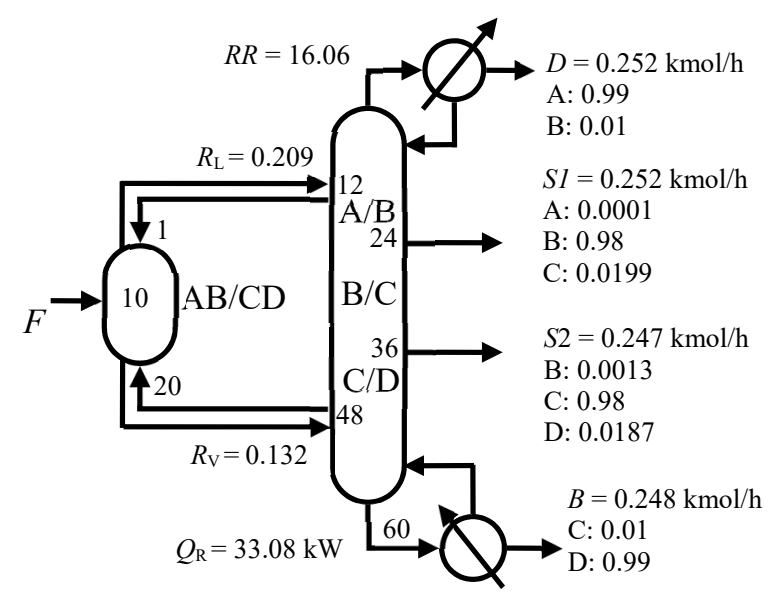

Figure 2. Thermally coupled configuration of the Kaibel DWC.

\section{Steady-State Design}

A mixture of n-pentane (A), n-hexane (B), n-heptane (C), and n-octane (D), as shown in Figure 2, was employed in the case study for the four-product Kaibel DWC. F, D, S1, S2, B, RR, $Q_{R}, R_{\mathrm{L}}$ and $R_{\mathrm{V}}$ represent the feed, distillate product, upper side product, lower side product, bottom product, reflux ratio, reboiler duty, liquid split ratio and vapor split ratio, respectively. The simulation software was Aspen Plus V8.0 (Bedford, Massachusetts, USA). Redlich-Kwong-Soave (RKS) was used as the property method. As shown in Figure 2, a sharp $A B / C D$ split was carried out in the prefractionator and three sharp splits including $\mathrm{A} / \mathrm{B}, \mathrm{B} / \mathrm{C}$, and $\mathrm{C} / \mathrm{D}$ splits were performed in the upper, middle, and lower part of the main column.

The molar composition specifications for the top and the bottom product were 0.99 , while those for the side products were 0.98 . To maintain all the four product specifications, four variables were varied, which were the top distillate flow rate $(D)$, the upper side product flow rate $(S 1)$, the lower side product flow rate (S2), and the liquid reflux rate $(L)$. With the reboiler duty $\left(Q_{R}\right)$ being the objective function, the liquid and vapor split ratios $\left(R_{\mathrm{L}}\right.$ and $\left.R_{\mathrm{V}}\right)$ were optimized. The optimal steady-state design is presented in Figure 2 and elaborated in detail in our previous study [13]. 


\section{Control Structures}

Two TC structures, two TDC structures, and two DTDC structures were studied for this paper. Proportional-integral (PI) controllers were used in the case study. In order to be more applicable in industries, only temperature controllers (no composition controllers) were used. The heat duty of the condenser controlled the top column pressure of the Kaibel DWC and the product flow rates controlled the levels. For those pressure and level controls, they were not shown in the control scheme figures and their tuning parameters used the suggested values from the literature [28,29].

There are six available manipulated variables $(u)$ besides the manipulated variables used for pressure control and level control:

1. Liquid reflux stream for the prefractionator $\left(L_{\mathrm{p}}\right)$

2. Vapor boilup stream for the prefractionator $\left(V_{\mathrm{p}}\right)$

3. Reflux stream for the main column $(L)$

4. Reboiler duty for the main column $\left(Q_{R}\right)$

5. Upper side product stream of the main column (S1)

6. Lower side product stream of the main column (S2).

Small changes $(+0.1 \%)$ in each available variable $(u)$ were made one at a time to find the sensitive tray temperatures to control. Figure 3 shows the sensitivity analysis profiles. The y-axis with the label "Gains (K)" in Figure 3 represents the steady-state change in the temperature at every stage. For stabilizing the control of the distillation columns, one temperature control loop was used for each split [27]. The prefractionator carried out a sharp $\mathrm{AB} / \mathrm{CD}$ split and required one temperature controller. The main column performed three sharp splits and required three temperature controllers. As shown in Figure 3, there was one sensitive temperature in the prefractionator and three sensitive temperatures in the main column. Therefore, the controlled variables in the temperature control structures were $\left[\mathrm{T}_{\mathrm{P}, 7}, \mathrm{~T}_{\mathrm{M}, 6}, \mathrm{~T}_{\mathrm{M}, 28}, \mathrm{~T}_{\mathrm{M}, 53}\right]$.

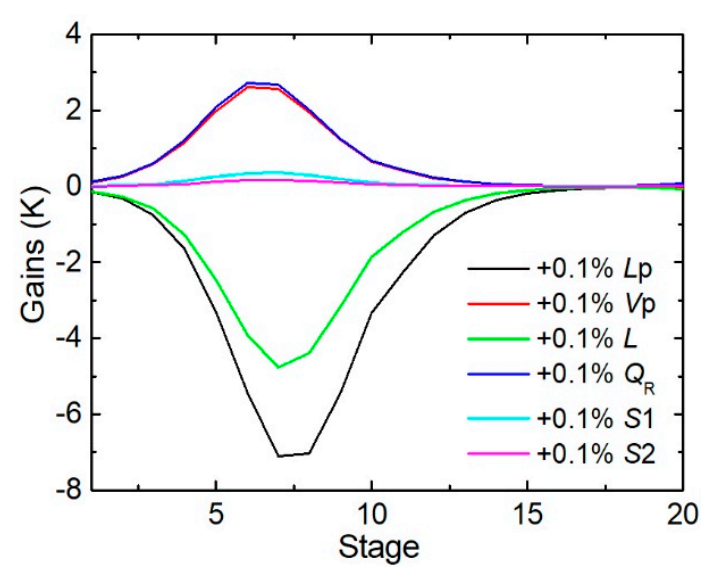

(a)

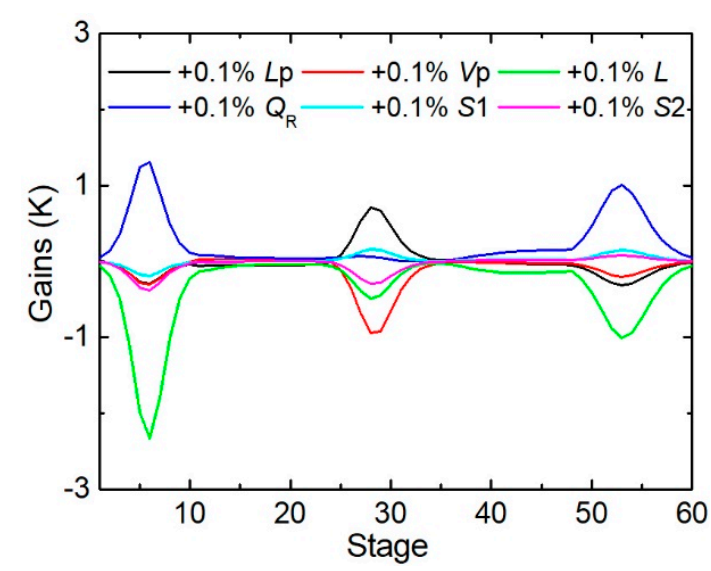

(b)

Figure 3. Sensitivity analysis profiles: (a) prefractionator; (b) main column.

Singular value decomposition analysis was used for choosing reference temperatures and sensitive temperatures for the temperature difference control structures [12]. Singular value decomposition analysis profiles are shown in Figure 4 . The formula $[\mathrm{U}, \mathrm{S}, \mathrm{V}]=$ svd (Gains,0) was used for SVD calculations. The y-axis with the label " $U$ " in Figure 4 means the matrix $U$ in the formula. In the temperature difference control structures, the controlled variables were temperature differences. In the prefractionator, it was the TD between the 19th and the 7th tray. In the main column, they were the TD between the 21st and the 6th tray, the TD between the 35th and the 28th tray, and the TD between the 53rd and the 48th tray. In summary, the controlled variables in the temperature difference 
control structures were $\left[T_{P, 19}-T_{P, 7}, T_{M, 21}-T_{M, 6}, T_{M, 35}-T_{M, 28}, T_{M, 53}-T_{M, 48}\right]$, as shown in Figure $4 a, b$. Similarly, as shown in Figure 4c,d, the controlled variables in the double temperature difference control structures were $\left[\left(\mathrm{T}_{\mathrm{P}, 19}-\mathrm{T}_{\mathrm{P}, 7}\right)-\left(\mathrm{T}_{\mathrm{P}, 7}-\mathrm{T}_{\mathrm{P}, 2}\right),\left(\mathrm{T}_{\mathrm{M}, 21}-\mathrm{T}_{\mathrm{M}, 6}\right)-\left(\mathrm{T}_{\mathrm{M}, 6}-\mathrm{T}_{\mathrm{M}, 2}\right),\left(\mathrm{T}_{\mathrm{M}, 35}-\mathrm{T}_{\mathrm{M}, 28}\right)-\left(\mathrm{T}_{\mathrm{M}, 28}-\right.\right.$ $\left.\left.\mathrm{T}_{\mathrm{M}, 22}\right),\left(\mathrm{T}_{\mathrm{M}, 60}-\mathrm{T}_{\mathrm{M}, 53}\right)-\left(\mathrm{T}_{\mathrm{M}, 53}-\mathrm{T}_{\mathrm{M}, 48}\right)\right]$.

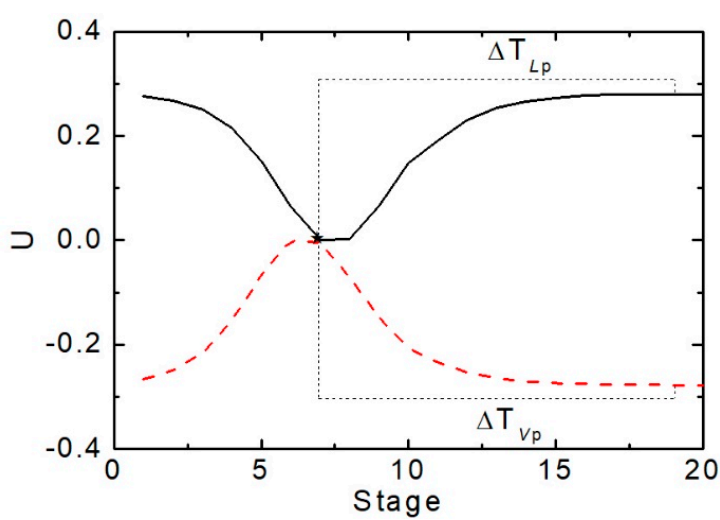

(a)

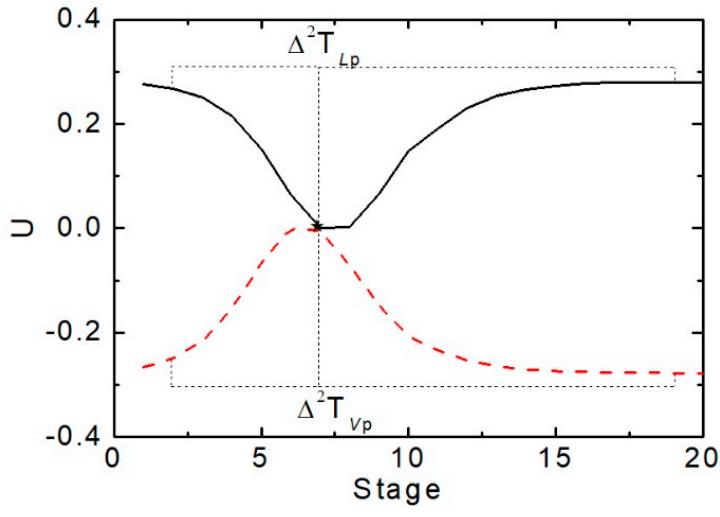

(c)

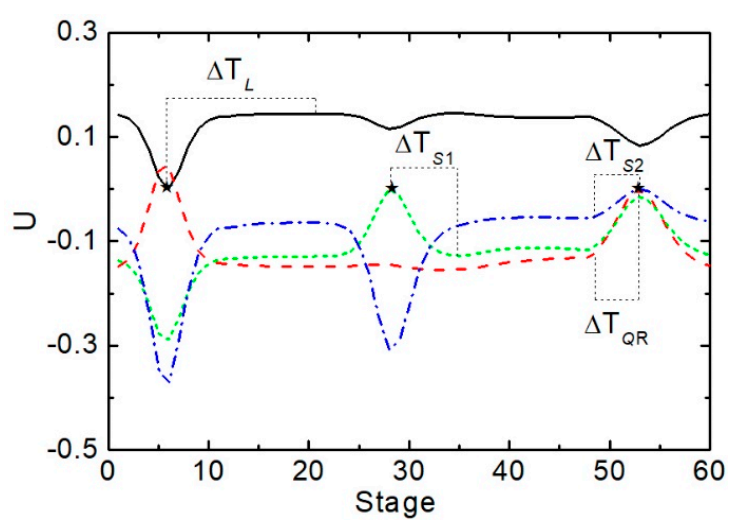

(b)

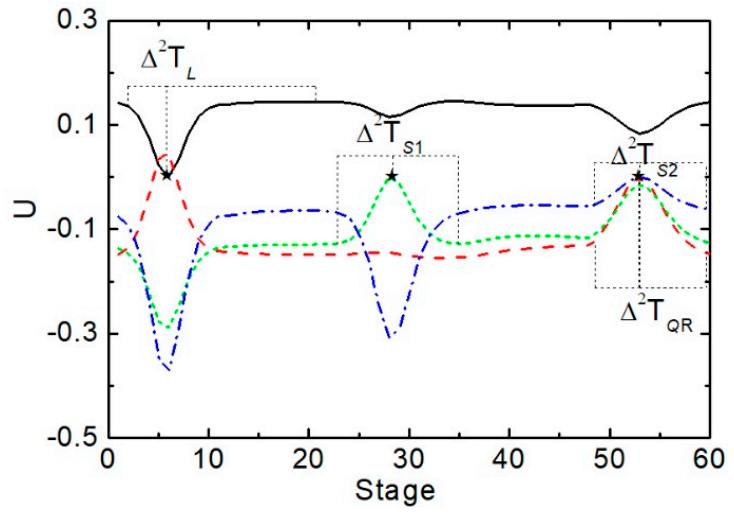

(d)

Figure 4. Singular value decomposition analysis profiles: (a) temperature difference for the prefractionator; (b) temperature difference for the main column; (c) double temperature difference for the prefractionator; (d) double temperature difference for the main column.

$L_{\mathrm{p}}$ was employed as the manipulated variable in TC1, TDC1, and DTDC1, while $V_{\mathrm{p}}$ was used as the manipulated variable in TC2, TDC2, and DTDC2. In the main column, $L, S 1$, and $S 2$ were used as manipulated variables according to the "pair close rule." As shown in Figures 3 and 4, S2 and $Q_{R}$ were both available as manipulated variables. However, the side product flow rates should not stay constant when feed rate disturbances or feed composition disturbances occur. In other words, almost all of component $C$ should flow into $S 2$ eventually. Therefore, we used $S 2$ as the manipulated variable and kept $Q_{\mathrm{R}}$ constant, as in the reported work by Dwivedi et al. [30]. In this way, we suppressed the excessive interactions among different control loops in the stripping section.

\subsection{Temperature Control}

Temperature control 1 (TC1) contained four temperature controllers, as illustrated in Figure 5. $R_{\mathrm{V}}$ was constant in TC1. For the temperature controller TCP, the manipulated variable (MV) was $L_{\mathrm{p}}$ in the prefractionator. The manipulated variables in the main column were $L, S 1$, and $S 2$. The corresponding controlled variables $(\mathrm{CV})$ were $\left[\mathrm{T}_{\mathrm{P}, 7}, \mathrm{~T}_{\mathrm{M}, 6}, \mathrm{~T}_{\mathrm{M}, 28}, \mathrm{~T}_{\mathrm{M}, 53}\right]$. 


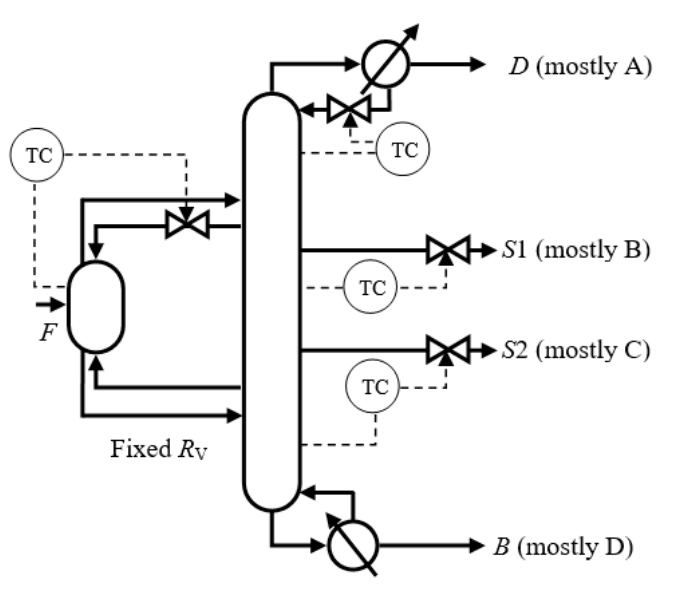

Figure 5. Temperature control 1 (TC1).

The controller gains and integral time constants were calculated using the Tyreus-Luyben method through close-loop tuning. The tuning sequence was as follows: first of all, the $L$ loop; second, the $S 1$ loop; third, the $S 2$ loop; and last, the $L_{\mathrm{p}}$ loop at the top of the prefractionator. The controllers tuning results of TC1 are presented in Table 1.

Table 1. Controllers tuning results of TC1.

\begin{tabular}{ccccc}
\hline Loop & CV & MV & Gain & Integral Time (min) \\
\hline TCP & $\mathrm{T}_{\mathrm{P}, 7}$ & $L_{\mathrm{p}}$ & 0.378 & 17.16 \\
TCM1 & $\mathrm{T}_{\mathrm{M}, 6}$ & $L$ & 0.316 & 9.24 \\
TCM2 & $\mathrm{T}_{\mathrm{M}, 28}$ & $S 1$ & 4.846 & 13.20 \\
TCM3 & $\mathrm{T}_{\mathrm{M}, 53}$ & $S 2$ & 4.915 & 19.80 \\
\hline
\end{tabular}

Temperature control 2 (TC2) is sketched in Figure 6. As the $R_{\mathrm{V}}$ had been experimentally verified as a manipulated variable in alcohols systems in the Kaibel DWC [31], it is of significance to study the effectiveness of temperature control with the vapor split being the MV in other systems. $R_{\mathrm{L}}$ was fixed in TC2. The tuning sequence of TC2 was similar with that of TC1 except that the $V_{\mathrm{p}}$ loop was used instead of the $L_{\mathrm{p}}$ loop. The tuning method of TC2 was the same as that of TC1. The tuning results for TC2 are listed in Table 2.

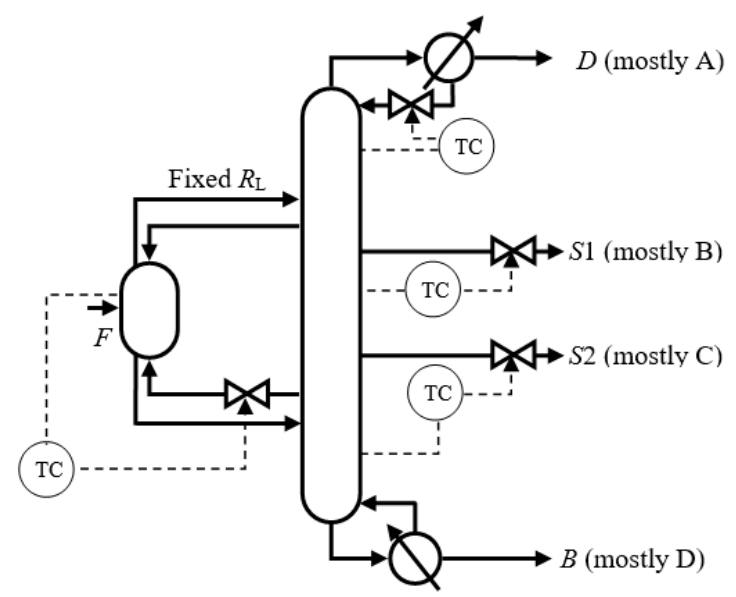

Figure 6. Temperature control 2 (TC2). 
Table 2. Controllers tuning results of TC2.

\begin{tabular}{ccccc}
\hline Loop & CV & MV & Gain & Integral Time (min) \\
\hline TCP & $\mathrm{T}_{\mathrm{P}, 7}$ & $V_{\mathrm{p}}$ & 0.817 & 10.56 \\
TCM1 & $\mathrm{T}_{\mathrm{M}, 6}$ & $L$ & 0.317 & 10.56 \\
TCM2 & $\mathrm{T}_{\mathrm{M}, 28}$ & $S 1$ & 3.293 & 17.16 \\
TCM3 & $\mathrm{T}_{\mathrm{M}, 53}$ & $S 2$ & 4.541 & 19.80 \\
\hline
\end{tabular}

\subsection{Temperature Difference Control}

To reduce the interference of column pressure changes and improve the dynamic results, temperature difference control 1 (TDC1) and temperature difference control structure 2 (TDC2) were introduced. TDC1 is illustrated in Figure 7.

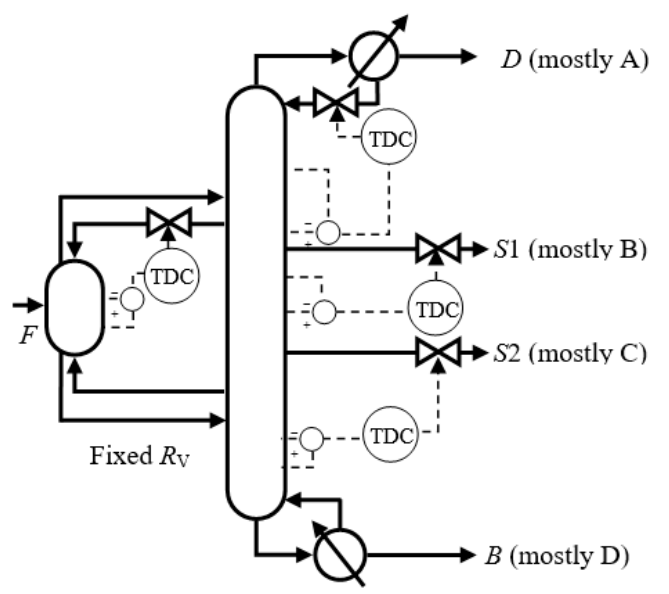

Figure 7. Temperature difference control 1 (TDC1).

In TDC1, $L_{\mathrm{p}}$ was utilized to control the TD between the 19th and the 7th tray in the prefractionator. As for the main column, $L$ was employed to control the TD between the 21st and the 6th tray, $S 1$ was applied to control the TD between the 35th and the 28th tray, and $S 2$ was utilized to control the TD between the $53 \mathrm{rd}$ and the 48 th tray. $R_{\mathrm{V}}$ remained constant in the operation. The tuning results for TDC1 are listed in Table 3.

Table 3. Controllers tuning results of TDC1.

\begin{tabular}{ccccc}
\hline Loop & CV & MV & Gain & Integral Time (min) \\
\hline TDCP & $\mathrm{T}_{\mathrm{P}, 19}-\mathrm{T}_{\mathrm{P}, 7}$ & $L_{\mathrm{p}}$ & 0.339 & 14.52 \\
TDCM1 & $\mathrm{T}_{\mathrm{M}, 21}-\mathrm{T}_{\mathrm{M}, 6}$ & $L$ & 0.207 & 9.24 \\
TDCM2 & $\mathrm{T}_{\mathrm{M}, 35}-\mathrm{T}_{\mathrm{M}, 28}$ & $S 1$ & 3.902 & 10.56 \\
TDCM3 & $\mathrm{T}_{\mathrm{M}, 53}-\mathrm{T}_{\mathrm{M}, 48}$ & $S 2$ & 2.416 & 15.84 \\
\hline
\end{tabular}

Temperature difference control 2 (TDC2) is sketched in Figure 8. The difference between TDC2 and TDC1 was that $V_{\mathrm{p}}$ was employed as the manipulated variable for TDCP. In TDC2, $R_{\mathrm{L}}$ remained constant. TDC2 was proposed in order to provide a possible control structure for the Kaibel DWC in the chemical industry. The tuning results for TDC2 are shown in Table 4. 


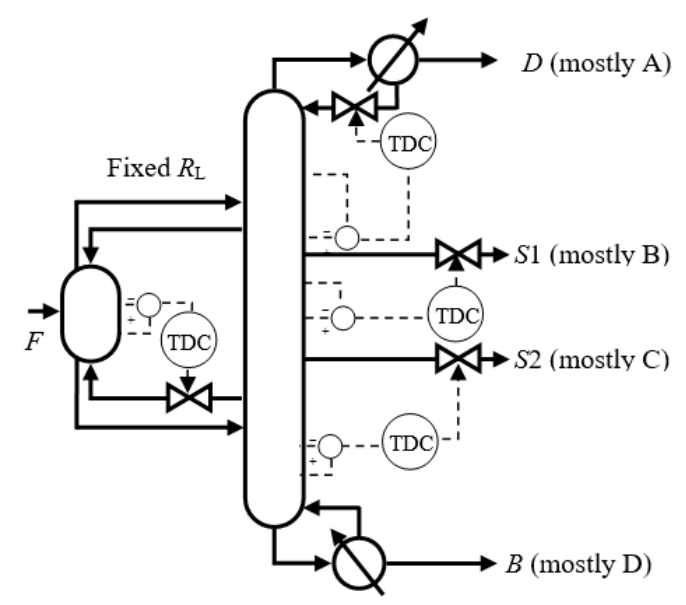

Figure 8. Temperature difference control 2 (TDC2).

Table 4. Controllers tuning results of TDC2.

\begin{tabular}{ccccc}
\hline Loop & CV & MV & Gain & Integral Time (min) \\
\hline TDCP & $\mathrm{T}_{\mathrm{P}, 19}-\mathrm{T}_{\mathrm{P}, 7}$ & $V_{\mathrm{p}}$ & 0.648 & 11.88 \\
TDCM1 & $\mathrm{T}_{\mathrm{M}, 21}-\mathrm{T}_{\mathrm{M}, 6}$ & $L$ & 0.182 & 9.24 \\
TDCM2 & $\mathrm{T}_{\mathrm{M}, 35}-\mathrm{T}_{\mathrm{M}, 28}$ & $S 1$ & 3.367 & 11.88 \\
TDCM3 & $\mathrm{T}_{\mathrm{M}, 53}-\mathrm{T}_{\mathrm{M}, 48}$ & $S 2$ & 2.473 & 19.80 \\
\hline
\end{tabular}

\subsection{Double Temperature Difference Control}

DTDC1, as shown in Figure 9, was introduced to achieve better results. In DTDC1, $L_{\mathrm{p}}$ was employed to control the double temperature difference $\left[\left(T_{P, 19}-T_{P, 7}\right)-\left(T_{P, 7}-T_{P, 2}\right)\right]$ in the prefractionator. $L$, $S 1$, and $S 2$ were used to control the double temperature differences $\left[\left(\mathrm{T}_{\mathrm{M}, 21}-\mathrm{T}_{\mathrm{M}, 6}\right)-\left(\mathrm{T}_{\mathrm{M}, 6}-\mathrm{T}_{\mathrm{M}, 2}\right)\right]$, $\left[\left(\mathrm{T}_{\mathrm{M}, 35}-\mathrm{T}_{\mathrm{M}, 28}\right)-\left(\mathrm{T}_{\mathrm{M}, 28}-\mathrm{T}_{\mathrm{M}, 22}\right)\right]$, and $\left[\left(\mathrm{T}_{\mathrm{M}, 60}-\mathrm{T}_{\mathrm{M}, 53}\right)-\left(\mathrm{T}_{\mathrm{M}, 53}-\mathrm{T}_{\mathrm{M}, 48}\right)\right]$ in the main column, respectively. $R_{\mathrm{V}}$ was constant. The tuning results of DTDC1 are listed in Table 5.

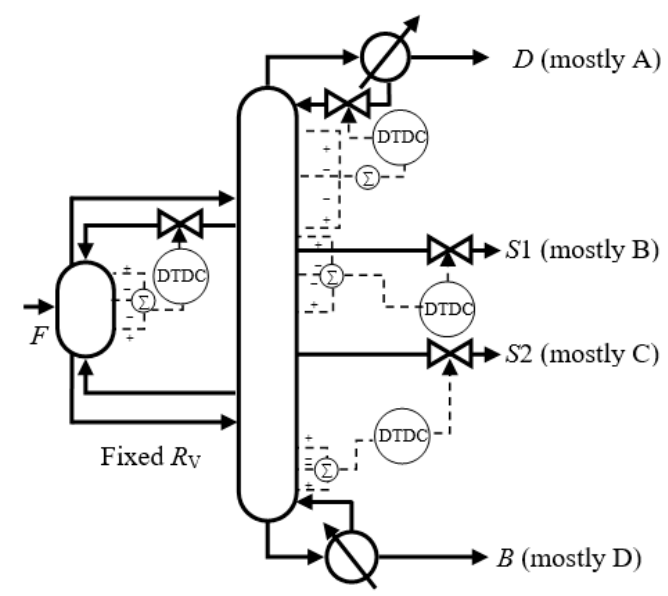

Figure 9. Double temperature difference control 1 (DTDC1).

Table 5. Controllers tuning results of DTDC1.

\begin{tabular}{ccccc}
\hline Loop & CV & MV & Gain & Integral Time (min) \\
\hline DTDCP & $\left(\mathrm{T}_{\mathrm{P}, 19}-\mathrm{T}_{\mathrm{P}, 7}\right)-\left(\mathrm{T}_{\mathrm{P}, 7}-\mathrm{T}_{\mathrm{P}, 2}\right)$ & $L_{\mathrm{p}}$ & 0.073 & 14.52 \\
DTDCM1 & $\left(\mathrm{T}_{\mathrm{M}, 21}-\mathrm{T}_{\mathrm{M}, 6}\right)-\left(\mathrm{T}_{\mathrm{M}, 6}-\mathrm{T}_{\mathrm{M}, 2}\right)$ & $L$ & 0.040 & 9.24 \\
DTDCM2 & $\left(\mathrm{T}_{\mathrm{M}, 35}-\mathrm{T}_{\mathrm{M}, 28}\right)-\left(\mathrm{T}_{\mathrm{M}, 28}-\mathrm{T}_{\mathrm{M}, 22}\right)$ & $S 1$ & 0.396 & 11.88 \\
DTDCM3 & $\left(\mathrm{T}_{\mathrm{M}, 60}-\mathrm{T}_{\mathrm{M}, 53}\right)-\left(\mathrm{T}_{\mathrm{M}, 53}-\mathrm{T}_{\mathrm{M}, 48}\right)$ & $S 2$ & 0.221 & 14.52 \\
\hline
\end{tabular}


DTDC2 is illustrated in Figure 10. The tuning results for TDC2 are shown in Table 6. The difference between DTDC2 and DTDC1 was that $V_{\mathrm{p}}$ was used as the MV for the double temperature difference controller DTDCP. $R_{\mathrm{L}}$ was constant. As the manipulation of the vapor split in the Kaibel DWC has been experimentally verified, DTDC2 could be a promising method.

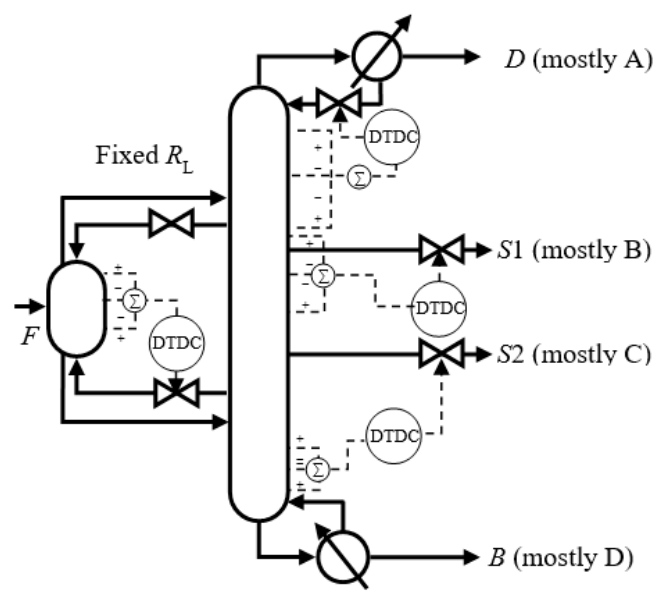

Figure 10. Double temperature difference control 2 (DTDC2).

Table 6. Controllers tuning results of DTDC2.

\begin{tabular}{ccccc}
\hline Loop & CV & MV & Gain & Integral Time (min) \\
\hline DTDCP & $\left(\mathrm{T}_{\mathrm{P}, 19}-\mathrm{T}_{\mathrm{T}, 7}\right)-\left(\mathrm{T}_{\mathrm{P}, 7}-\mathrm{T}_{\mathrm{P}, 2}\right)$ & $V_{\mathrm{p}}$ & 0.109 & 10.56 \\
DTDCM1 & $\left(\mathrm{T}_{\mathrm{M}, 21}-\mathrm{T}_{\mathrm{M}, 6}\right)-\left(\mathrm{T}_{\mathrm{M}, 6}-\mathrm{T}_{\mathrm{M}, 2}\right)$ & $L$ & 0.040 & 9.24 \\
DTDCM2 & $\left(\mathrm{T}_{\mathrm{M}, 35}-\mathrm{T}_{\mathrm{M}, 28}\right)-\left(\mathrm{T}_{\mathrm{M}, 28}-\mathrm{T}_{\mathrm{M}, 22}\right)$ & $S 1$ & 0.375 & 10.56 \\
DTDCM3 & $\left(\mathrm{T}_{\mathrm{M}, 60}-\mathrm{T}_{\mathrm{M}, 53}\right)-\left(\mathrm{T}_{\mathrm{M}, 53}-\mathrm{T}_{\mathrm{M}, 48}\right)$ & $S 2$ & 0.228 & 14.52 \\
\hline
\end{tabular}

\section{Results}

The dynamic performances using TC and TDC against $\pm 10 \%$ feed disturbances at $0.5 \mathrm{~h}$ are presented in Figure 11. Tables 7-9 show the steady-state deviation, maximum transient deviation, and settling time for the step disturbances in feed compositions and feed flow rates. For example, the $+10 \%$ feed composition increase of A involved A increasing from 0.25 to 0.275 , and the other three components were all equal. The positive responses are represented by black curves and negative responses by gray curves. The types of the line for black curves and gray curves are identical. Therefore, gray curves are not described in the legend in each figure in order to be concise and clear. The dynamic performances were all very smooth, although there were a few more oscillations when $\pm 10 \% \mathrm{~F}$ disturbances occur. The steady-state and the maximum deviations (SD and $\mathrm{MD}$ ) of the top product $\mathrm{X}_{\mathrm{D}, \mathrm{A}}$ were smaller using temperature difference controls (TDC1 and TDC2) in most cases. For the bottom product $\mathrm{X}_{\mathrm{B}, \mathrm{D}}$, the SD and MD were reduced by employing temperature difference controls (TDC1 and TDC2) in all kinds of feed disturbances. Therefore, temperature difference control is a better choice if the top and the bottom products are more important than the side products. For the upper side product $\mathrm{X}_{\mathrm{S} 1, \mathrm{~B}}$, the SD and MD were suppressed using temperature control (TC1 and TC2) in most cases. Different from the other three products, the SD and MD of $\mathrm{X}_{\mathrm{S} 2, \mathrm{C}}$ were reduced by employing control structures with an active $R_{\mathrm{L}}$ (TC1 and TDC1) in most cases. The SD and MD of the D and B were smaller than those of $S 1$ and $S 2$ because the product composition specifications were different.

As for DTDC, although the dynamic results for the upper side product using the control structures were similarly good, the dynamic performances for the lower side product using the control structures were very different. In order to be more clear, the dynamic performances of the four products using TDC and DTDC against $\pm 10 \%$ feed disturbances at $0.5 \mathrm{~h}$ are presented in Figure 12. For the lower side product $\mathrm{X}_{\mathrm{S} 2, \mathrm{C}}$, control structures with an active vapor split (TDC2 and DTDC2) were better when 
feed compositions of B or C occurred, while control structures with an active liquid split (TDC1 and DTDC1) were better when other feed disturbances occurred. The SD and MD of $X_{S 2, C}$ were all larger than those of $\mathrm{X}_{\mathrm{S1}, \mathrm{B}}$. Also, the SD and MD of the bottom product were mostly larger than those of the top product. The reason for the inferiority of the lower side product and bottom product was the serious coupling in the stripping section. The $S D$ and $M D$ of the top product $X_{D, A}$ were reduced when employing control structures with an active $R_{\mathrm{V}}$ (TDC2 and DTDC2). For the bottom product $\mathrm{X}_{\mathrm{B}, \mathrm{D}}$, the $\mathrm{SD}$ and MD were reduced when employing control structures with an active $R_{\mathrm{L}}$ (TDC1 and DTDC1). Therefore, control structures with an active $R_{\mathrm{L}}$ are the better choices if $S 2$ and $B$ are more important than $D$ and $S 1$. For the settling time, DTDC structures were best among the six control structures. For the deviations, this may be due to the fact that the sensitive temperatures could not accurately indicate the compositions in the multicomponent distillation systems. Besides, the pressure variations may aggravate the inconsistencies between the sensitive temperatures and the compositions. Pressure-compensated temperature difference control may be explored in the future to compensate for the pressure variations.
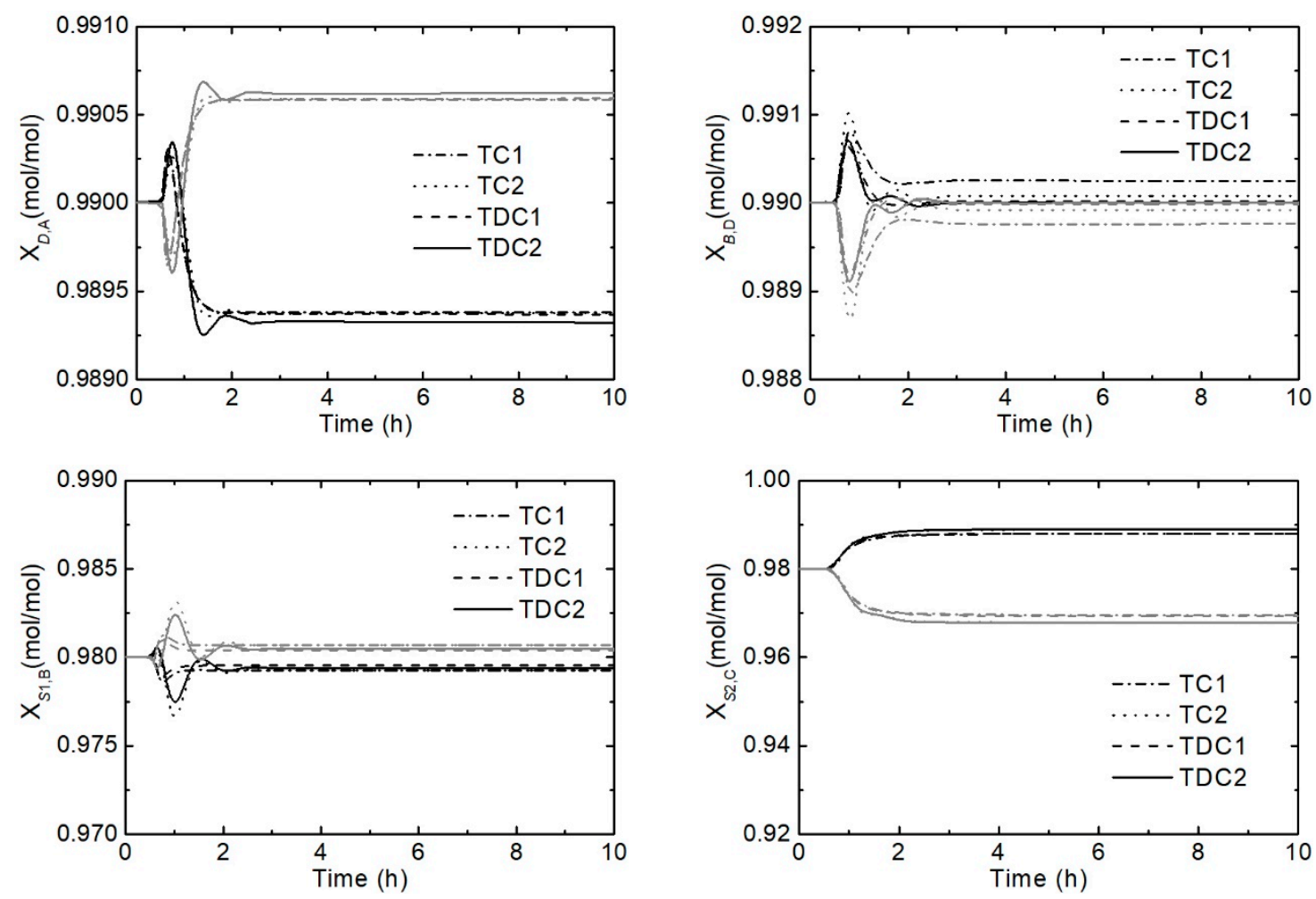

(a)

Figure 11. Cont. 

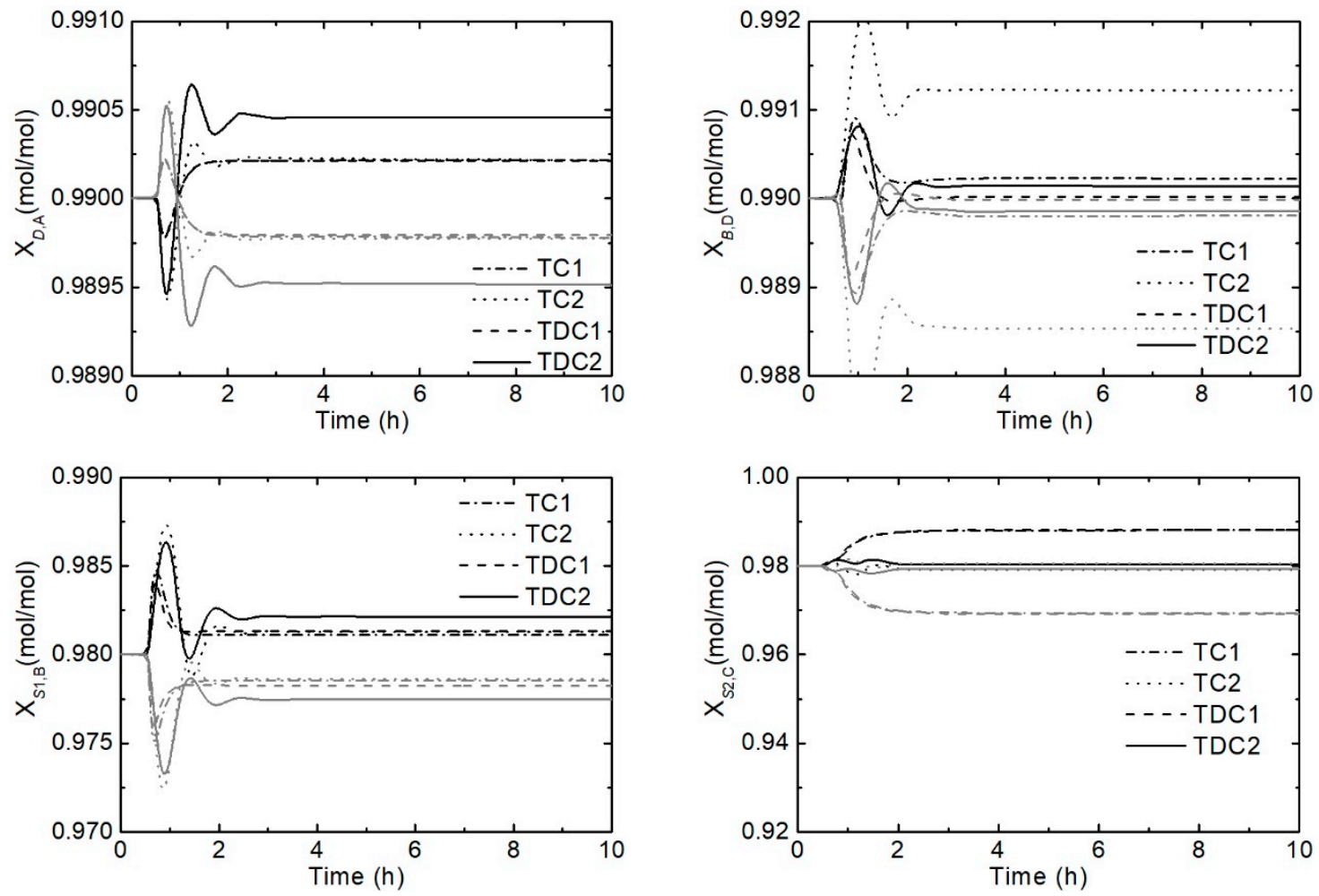

(b)
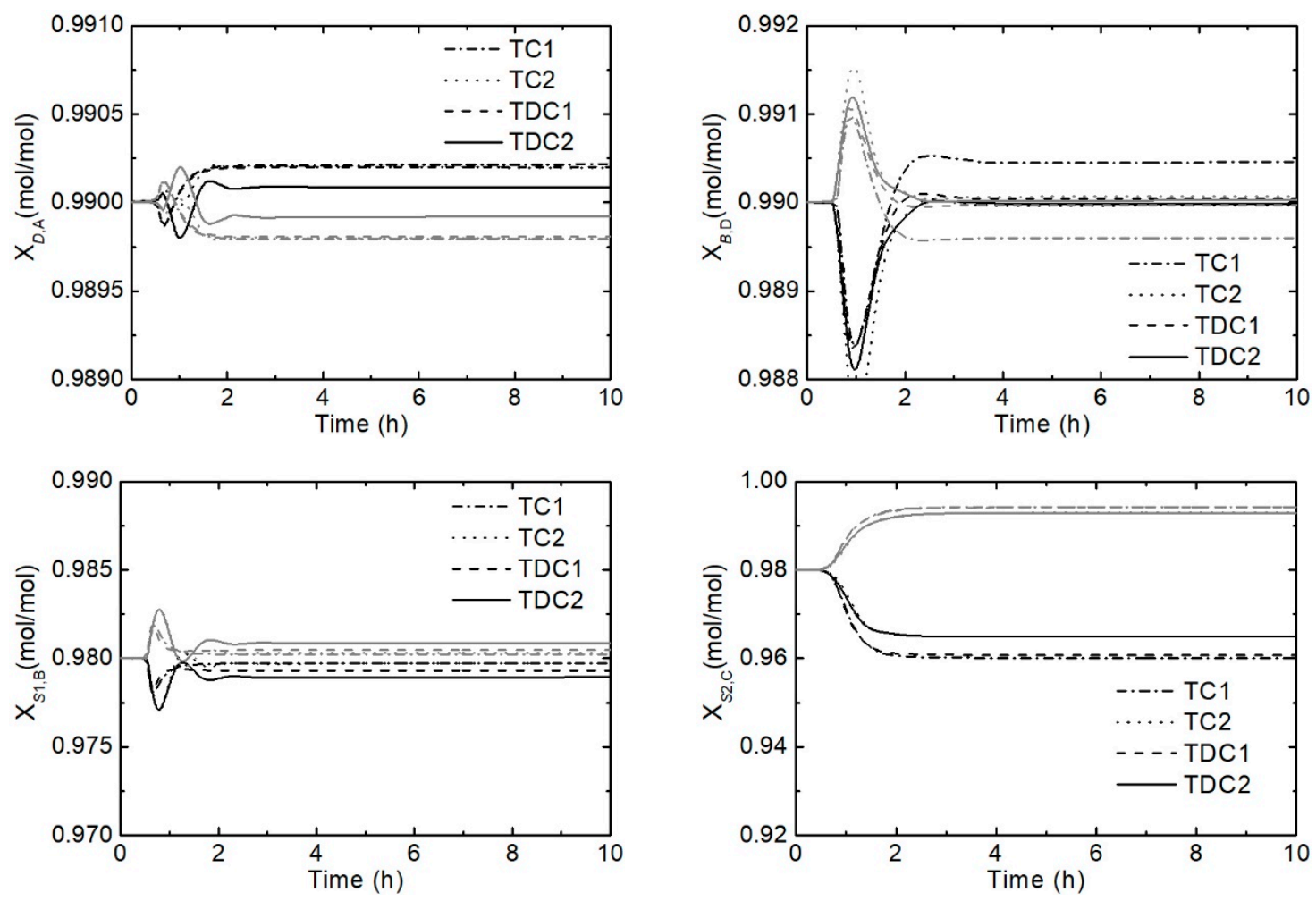

(c)

Figure 11. Cont. 

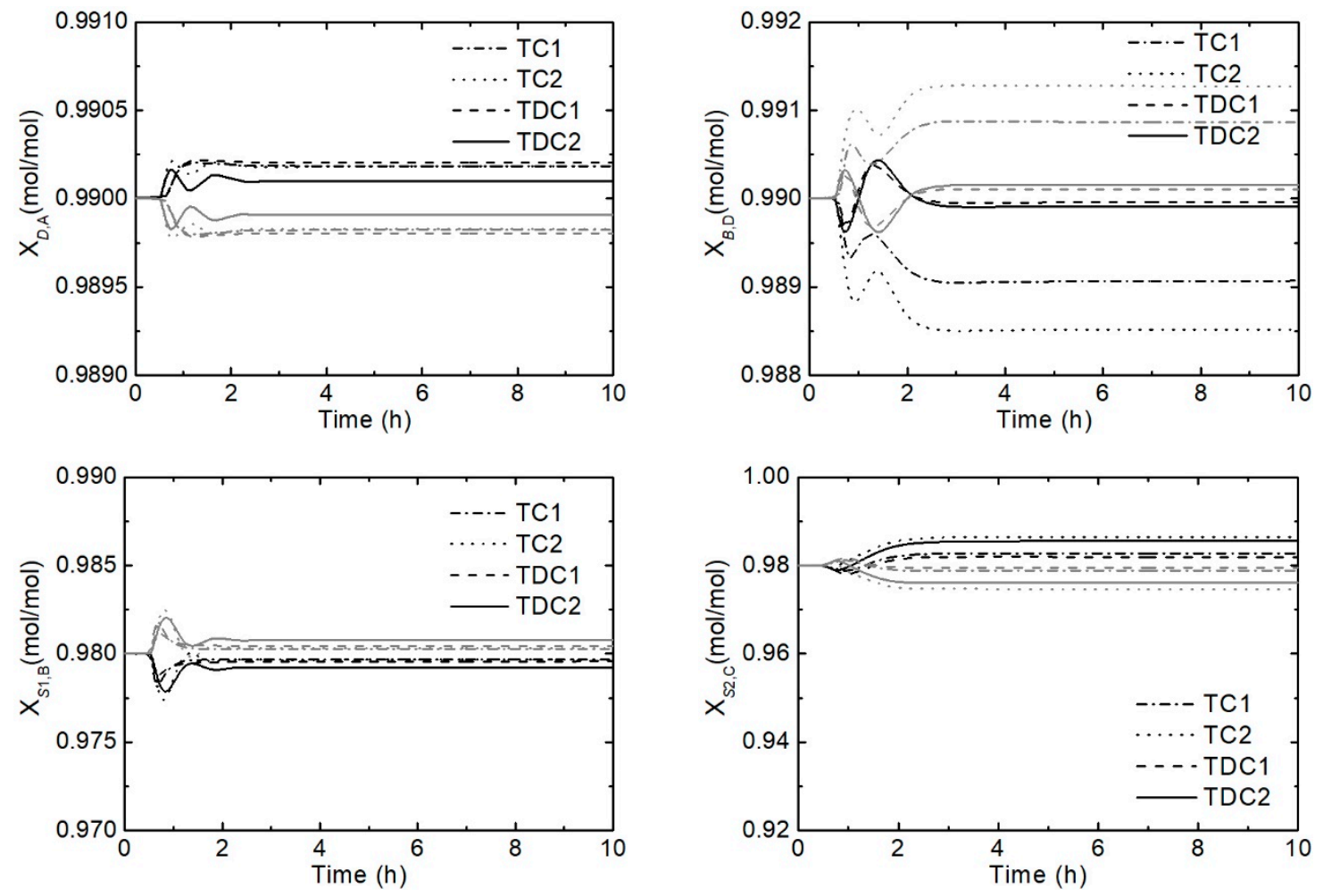

(d)
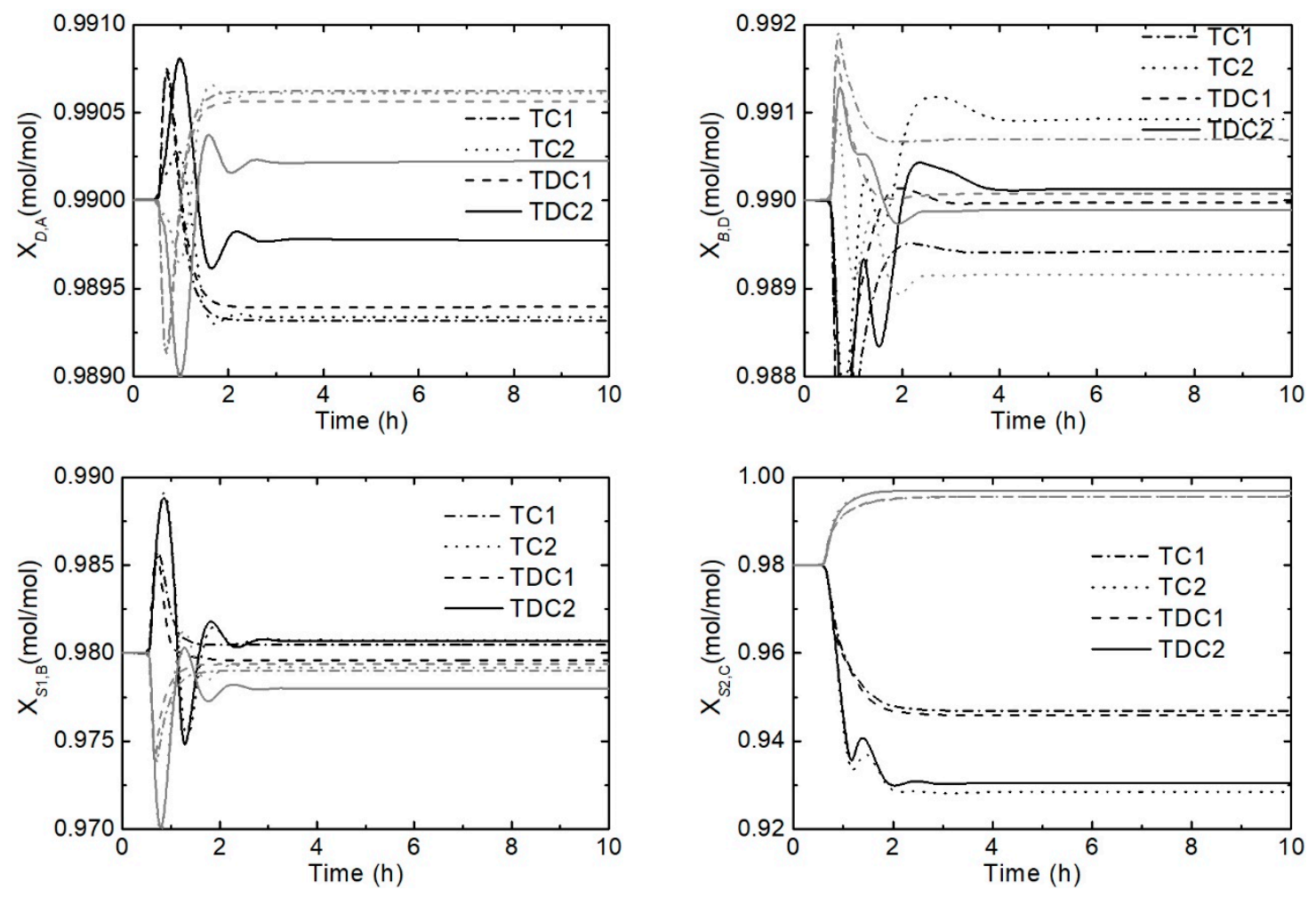

(e)

Figure 11. TC versus TDC: Dynamic results against $\pm 10 \%$ feed compositions and feed flow rate $(\mathrm{F})$ disturbances: (a) A disturbances, (b) B disturbances, (c) C disturbances, (d) D disturbances, and (e) F disturbances. 
Table 7. Steady-state deviations of the four products $\left(\Delta \mathrm{X}_{\mathrm{DA}}, \Delta \mathrm{X}_{S 1 \mathrm{~B}}, \Delta \mathrm{X}_{S 2 \mathrm{C}}, \Delta \mathrm{X}_{\mathrm{BD}}\right)$.

\begin{tabular}{|c|c|c|c|c|c|c|c|}
\hline Disturbance & Product & TC1 (\%) & TC2 (\%) & TDC1 (\%) & TDC2 (\%) & DTDC1 (\%) & DTDC2 (\%) \\
\hline \multirow[t]{4}{*}{$+10 \% \mathrm{~A}$} & A & -0.062 & -0.062 & -0.063 & -0.068 & -0.065 & -0.068 \\
\hline & B & -0.073 & -0.073 & -0.047 & -0.061 & -0.048 & -0.058 \\
\hline & $\mathrm{C}$ & 0.794 & 0.892 & 0.805 & 0.895 & 0.796 & 0.887 \\
\hline & $\mathrm{D}$ & 0.025 & 0.008 & 0.002 & 0.001 & 0.016 & 0.014 \\
\hline \multirow[t]{4}{*}{$-10 \% \mathrm{~A}$} & A & 0.059 & 0.059 & 0.059 & 0.062 & 0.061 & 0.063 \\
\hline & B & 0.069 & 0.071 & 0.038 & 0.049 & 0.043 & 0.051 \\
\hline & $\mathrm{C}$ & -1.045 & -1.210 & -1.071 & -1.221 & -1.050 & -1.201 \\
\hline & $\mathrm{D}$ & -0.024 & -0.008 & -0.001 & 0.000 & -0.015 & -0.013 \\
\hline \multirow[t]{4}{*}{$+10 \% \mathrm{~B}$} & A & 0.021 & 0.022 & 0.021 & 0.046 & 0.022 & 0.035 \\
\hline & B & 0.113 & 0.130 & 0.135 & 0.215 & 0.116 & 0.183 \\
\hline & $\mathrm{C}$ & 0.807 & -0.086 & 0.816 & 0.034 & 0.810 & 0.018 \\
\hline & $\mathrm{D}$ & 0.023 & 0.122 & 0.002 & 0.014 & 0.016 & 0.033 \\
\hline \multirow[t]{4}{*}{$-10 \% \mathrm{~B}$} & A & -0.022 & -0.023 & -0.020 & -0.049 & -0.022 & -0.037 \\
\hline & B & -0.147 & -0.138 & -0.175 & -0.254 & -0.154 & -0.212 \\
\hline & $\mathrm{C}$ & -1.065 & 0.058 & -1.089 & -0.061 & -1.073 & -0.043 \\
\hline & $\mathrm{D}$ & -0.019 & -0.146 & -0.001 & -0.014 & -0.014 & -0.034 \\
\hline \multirow[t]{4}{*}{$+10 \% \mathrm{C}$} & A & 0.021 & 0.020 & 0.020 & 0.009 & 0.021 & 0.015 \\
\hline & B & -0.029 & -0.030 & -0.070 & -0.106 & -0.054 & -0.082 \\
\hline & $\mathrm{C}$ & -1.990 & -1.507 & -1.924 & -1.509 & -1.959 & -1.540 \\
\hline & $\mathrm{D}$ & 0.046 & -0.003 & 0.004 & -0.001 & 0.027 & 0.019 \\
\hline \multirow[t]{4}{*}{$-10 \% \mathrm{C}$} & A & -0.021 & -0.021 & -0.019 & -0.008 & -0.021 & -0.015 \\
\hline & B & 0.024 & 0.029 & 0.047 & 0.088 & 0.040 & 0.071 \\
\hline & $\mathrm{C}$ & 1.427 & 1.296 & 1.418 & 1.293 & 1.422 & 1.301 \\
\hline & $\mathrm{D}$ & -0.040 & 0.007 & -0.003 & 0.002 & -0.024 & -0.018 \\
\hline \multirow[t]{4}{*}{$+10 \% \mathrm{D}$} & A & 0.018 & 0.018 & 0.021 & 0.010 & 0.021 & 0.015 \\
\hline & B & -0.033 & -0.034 & -0.043 & -0.079 & -0.038 & -0.065 \\
\hline & $\mathrm{C}$ & 0.268 & 0.648 & 0.193 & 0.552 & 0.241 & 0.595 \\
\hline & $\mathrm{D}$ & -0.093 & -0.148 & -0.004 & -0.009 & -0.058 & -0.066 \\
\hline \multirow[t]{4}{*}{$-10 \% \mathrm{D}$} & $\mathrm{A}$ & -0.018 & -0.017 & -0.020 & -0.009 & -0.020 & -0.014 \\
\hline & B & 0.028 & 0.032 & 0.045 & 0.079 & 0.037 & 0.064 \\
\hline & $\mathrm{C}$ & -0.116 & -0.531 & -0.044 & -0.393 & -0.087 & -0.448 \\
\hline & $\mathrm{D}$ & 0.087 & 0.127 & 0.011 & 0.015 & 0.057 & 0.064 \\
\hline \multirow[t]{4}{*}{$+10 \% \mathrm{~F}$} & A & -0.068 & -0.066 & -0.060 & -0.023 & -0.067 & -0.046 \\
\hline & B & 0.047 & 0.075 & -0.039 & 0.071 & 0.026 & 0.118 \\
\hline & $\mathrm{C}$ & -3.319 & -5.154 & -3.419 & -4.949 & -3.349 & -4.884 \\
\hline & $\mathrm{D}$ & -0.058 & 0.093 & -0.003 & 0.013 & -0.042 & -0.016 \\
\hline
\end{tabular}

Table 8. Maximum transient deviations of the four products $\left(\Delta \mathrm{X}_{\mathrm{DA}}, \Delta \mathrm{X}_{\mathrm{S} 1 \mathrm{~B}}, \Delta \mathrm{X}_{\mathrm{S} 2 \mathrm{C}}, \Delta \mathrm{X}_{\mathrm{BD}}\right)$.

\begin{tabular}{cccccccc}
\hline Disturbance & Product & TC1 (\%) & TC2 (\%) & TDC1 (\%) & TDC2 (\%) & DTDC1 (\%) & DTDC2 (\%) \\
\hline$+10 \%$ A & A & -0.062 & -0.064 & -0.063 & -0.075 & -0.065 & -0.069 \\
& B & -0.138 & -0.333 & -0.119 & -0.251 & -0.167 & -0.218 \\
& C & 0.794 & 0.892 & 0.805 & 0.895 & 0.796 & 0.887 \\
$-10 \%$ A & D & 0.081 & 0.102 & 0.065 & 0.071 & 0.061 & 0.064 \\
& A & 0.059 & 0.061 & 0.059 & 0.069 & 0.061 & 0.064 \\
& B & 0.123 & 0.314 & 0.103 & 0.241 & 0.176 & 0.223 \\
$+10 \%$ B & C & -1.045 & -1.210 & -1.071 & -1.221 & -1.050 & -1.201 \\
& D & -0.102 & -0.131 & -0.081 & -0.089 & -0.077 & -0.082 \\
& A & -0.022 & -0.057 & -0.022 & 0.064 & 0.022 & 0.043 \\
$-10 \%$ B & B & 0.477 & 0.730 & 0.409 & 0.634 & 0.480 & 0.662 \\
& C & 0.807 & -0.187 & 0.816 & 0.143 & 0.810 & 0.168 \\
& D & 0.091 & 0.206 & 0.073 & 0.081 & 0.079 & 0.089 \\
& A & -0.022 & 0.055 & 0.022 & -0.072 & -0.022 & -0.045 \\
& B & -0.507 & -0.761 & -0.417 & -0.672 & -0.519 & -0.664 \\
& C & -1.065 & 0.158 & -1.089 & -0.164 & -1.073 & -0.191 \\
\hline
\end{tabular}


Table 8. Cont.

\begin{tabular}{cccccccc}
\hline Disturbance & Product & TC1 (\%) & TC2 (\%) & TDC1 (\%) & TDC2 (\%) & DTDC1 (\%) & DTDC2 (\%) \\
\hline$+10 \%$ C & A & 0.021 & 0.021 & 0.020 & -0.020 & 0.021 & 0.017 \\
& B & -0.190 & -0.296 & -0.192 & -0.290 & -0.221 & -0.280 \\
& C & -1.990 & -1.507 & -1.924 & -1.509 & -1.959 & -1.540 \\
$-10 \%$ C & D & -0.161 & -0.252 & -0.165 & -0.189 & -0.138 & -0.150 \\
& A & -0.021 & -0.021 & -0.019 & 0.020 & -0.021 & -0.016 \\
& B & 0.186 & 0.280 & 0.189 & 0.277 & 0.214 & 0.280 \\
& C & 1.427 & 1.296 & 1.418 & 1.293 & 1.422 & 1.301 \\
$+10 \%$ D & D & 0.098 & 0.153 & 0.108 & 0.119 & 0.089 & 0.091 \\
& A & 0.021 & 0.021 & 0.022 & 0.016 & 0.021 & 0.017 \\
& B & -0.184 & -0.261 & -0.123 & -0.214 & -0.180 & -0.228 \\
$-10 \%$ D & C & 0.272 & 0.648 & 0.196 & 0.552 & 0.244 & 0.595 \\
& D & -0.095 & -0.150 & 0.037 & 0.043 & -0.059 & -0.066 \\
& A & -0.020 & -0.022 & -0.021 & -0.017 & -0.020 & -0.016 \\
& B & 0.176 & 0.250 & 0.121 & 0.205 & 0.172 & 0.222 \\
$+10 \%$ F & C & -0.122 & -0.531 & 0.172 & -0.393 & 0.149 & -0.448 \\
& D & 0.088 & 0.128 & -0.033 & -0.038 & 0.057 & 0.065 \\
& A & 0.073 & -0.070 & 0.076 & 0.081 & -0.067 & -0.053 \\
& B & 0.573 & 0.912 & 0.562 & 0.881 & 0.639 & 0.899 \\
& C & -3.319 & -5.187 & -3.419 & -5.014 & -3.349 & -5.109 \\
\hline
\end{tabular}

Table 9. Settling time of the four products $\left(X_{D A}, X_{S 1 B}, X_{S 2 C}, X_{B D}\right)$.

\begin{tabular}{|c|c|c|c|c|c|c|c|}
\hline Disturbance & Product & TC1 & TC2 & TDC1 & TDC2 & DTDC1 & DTDC2 \\
\hline \multirow[t]{4}{*}{$+10 \% \mathrm{~A}$} & A & 1.26 & 1.24 & 1.28 & 1.19 & 1.07 & 1.06 \\
\hline & B & 1.08 & 2.21 & 1.06 & 2.23 & 1.00 & 2.18 \\
\hline & $\mathrm{C}$ & 3.36 & 3.11 & 3.34 & 3.04 & 3.39 & 3.09 \\
\hline & $\mathrm{D}$ & 1.33 & 1.41 & 1.25 & 1.13 & 1.16 & 1.00 \\
\hline \multirow[t]{4}{*}{$-10 \% \mathrm{~A}$} & A & 1.24 & 1.24 & 1.24 & 1.18 & 1.04 & 1.04 \\
\hline & B & 1.09 & 2.21 & 1.09 & 2.24 & 1.01 & 2.21 \\
\hline & $\mathrm{C}$ & 3.83 & 3.05 & 3.70 & 3.06 & 3.69 & 2.97 \\
\hline & $\mathrm{D}$ & 1.43 & 1.44 & 1.32 & 1.76 & 1.24 & 1.62 \\
\hline \multirow[t]{4}{*}{$+10 \%$ B } & A & 1.13 & 1.30 & 1.12 & 1.75 & 0.91 & 0.93 \\
\hline & B & 1.27 & 2.57 & 1.06 & 2.63 & 1.11 & 2.65 \\
\hline & $\mathrm{C}$ & 3.24 & 2.06 & 3.19 & 1.98 & 3.16 & 2.63 \\
\hline & $\mathrm{D}$ & 1.40 & 1.98 & 1.31 & 1.90 & 1.21 & 2.17 \\
\hline \multirow[t]{4}{*}{$-10 \% \mathrm{~B}$} & $\mathrm{~A}$ & 1.17 & 1.33 & 1.12 & 1.81 & 0.91 & 0.94 \\
\hline & B & 1.40 & 2.15 & 1.12 & 2.50 & 1.24 & 2.53 \\
\hline & $\mathrm{C}$ & 3.34 & 2.07 & 3.32 & 2.05 & 3.29 & 1.81 \\
\hline & $\mathrm{D}$ & 1.52 & 2.03 & 1.38 & 1.97 & 1.28 & 1.82 \\
\hline \multirow[t]{4}{*}{$+10 \% \mathrm{C}$} & A & 1.12 & 1.31 & 1.12 & 1.32 & 0.86 & 1.03 \\
\hline & B & 1.34 & 1.98 & 0.86 & 1.97 & 1.05 & 2.00 \\
\hline & $\mathrm{C}$ & 3.09 & 2.70 & 2.99 & 2.77 & 2.92 & 2.60 \\
\hline & $\mathrm{D}$ & 1.99 & 2.03 & 1.84 & 2.12 & 1.71 & 1.49 \\
\hline \multirow[t]{4}{*}{$-10 \%$ C } & A & 1.14 & 1.36 & 1.12 & 1.33 & 0.88 & 1.09 \\
\hline & B & 1.30 & 2.03 & 0.93 & 1.98 & 1.05 & 2.40 \\
\hline & $\mathrm{C}$ & 3.01 & 3.24 & 3.15 & 3.20 & 3.07 & 3.28 \\
\hline & D & 1.78 & 1.75 & 1.69 & 1.94 & 1.55 & 1.37 \\
\hline \multirow[t]{4}{*}{$+10 \% \mathrm{D}$} & A & 0.76 & 0.59 & 0.80 & 0.11 & 0.71 & 0.58 \\
\hline & B & 1.22 & 1.90 & 1.44 & 1.97 & 1.22 & 2.01 \\
\hline & $\mathrm{C}$ & 2.47 & 3.06 & 2.54 & 3.10 & 2.52 & 3.21 \\
\hline & $\mathrm{D}$ & 2.09 & 2.11 & 2.04 & 2.18 & 1.90 & 1.85 \\
\hline \multirow[t]{4}{*}{$-10 \% \mathrm{D}$} & A & 0.75 & 0.58 & 0.77 & -0.03 & 0.70 & 0.57 \\
\hline & B & 1.19 & 1.98 & 1.19 & 1.63 & 1.14 & 2.04 \\
\hline & $\mathrm{C}$ & 1.97 & 2.39 & 1.85 & 2.29 & 1.80 & 2.38 \\
\hline & $\mathrm{D}$ & 2.09 & 2.07 & 2.03 & 2.11 & 1.87 & 1.83 \\
\hline \multirow[t]{4}{*}{$+10 \% \mathrm{~F}$} & A & 1.44 & 1.46 & 1.43 & 1.80 & 1.24 & 1.34 \\
\hline & B & 1.48 & 2.58 & 1.63 & 2.63 & 1.18 & 3.08 \\
\hline & $\mathrm{C}$ & 3.41 & 3.80 & 3.30 & 3.51 & 3.17 & 3.33 \\
\hline & $\mathrm{D}$ & 1.69 & 3.46 & 2.42 & 3.36 & 2.56 & 2.97 \\
\hline
\end{tabular}



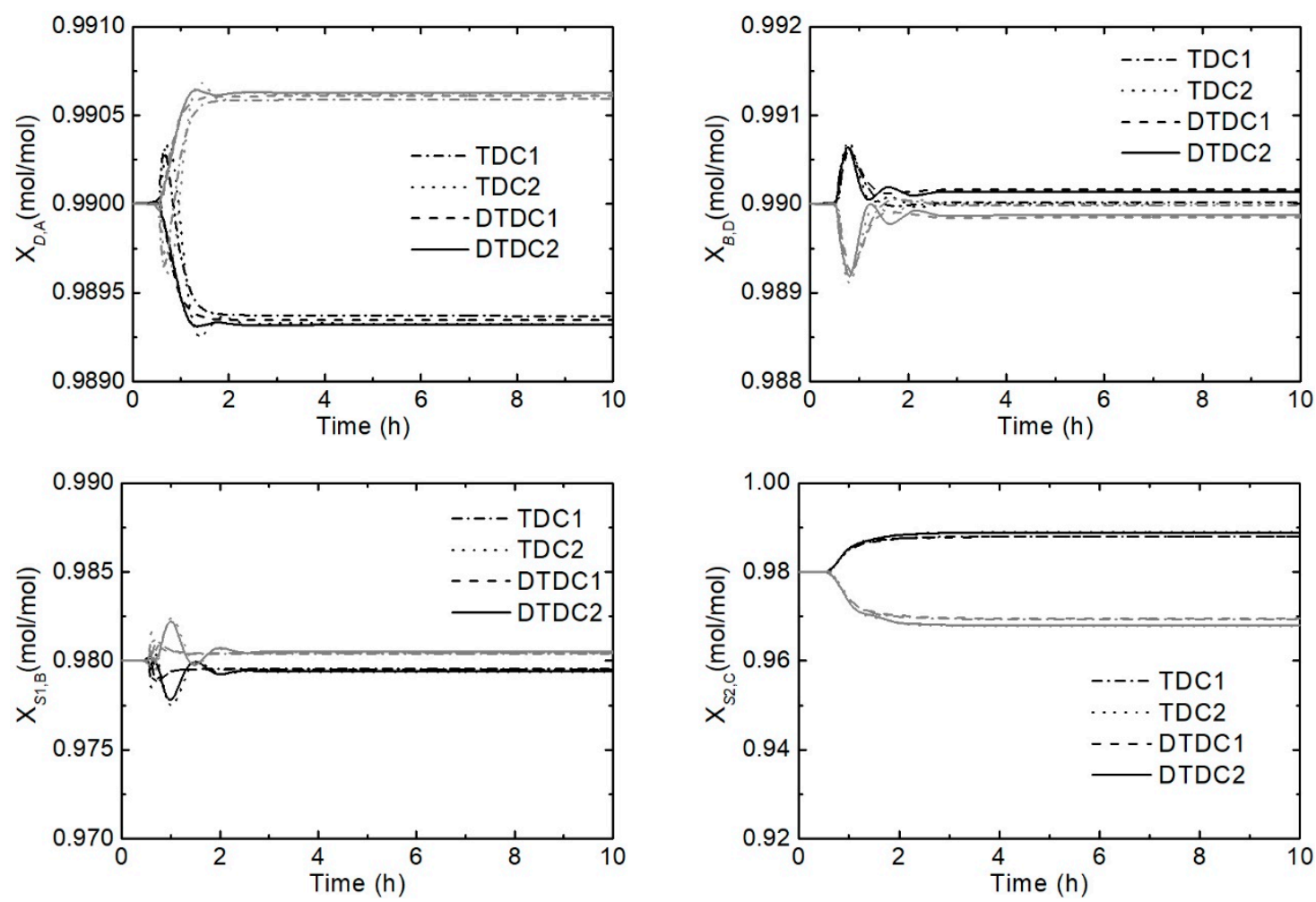

(a)
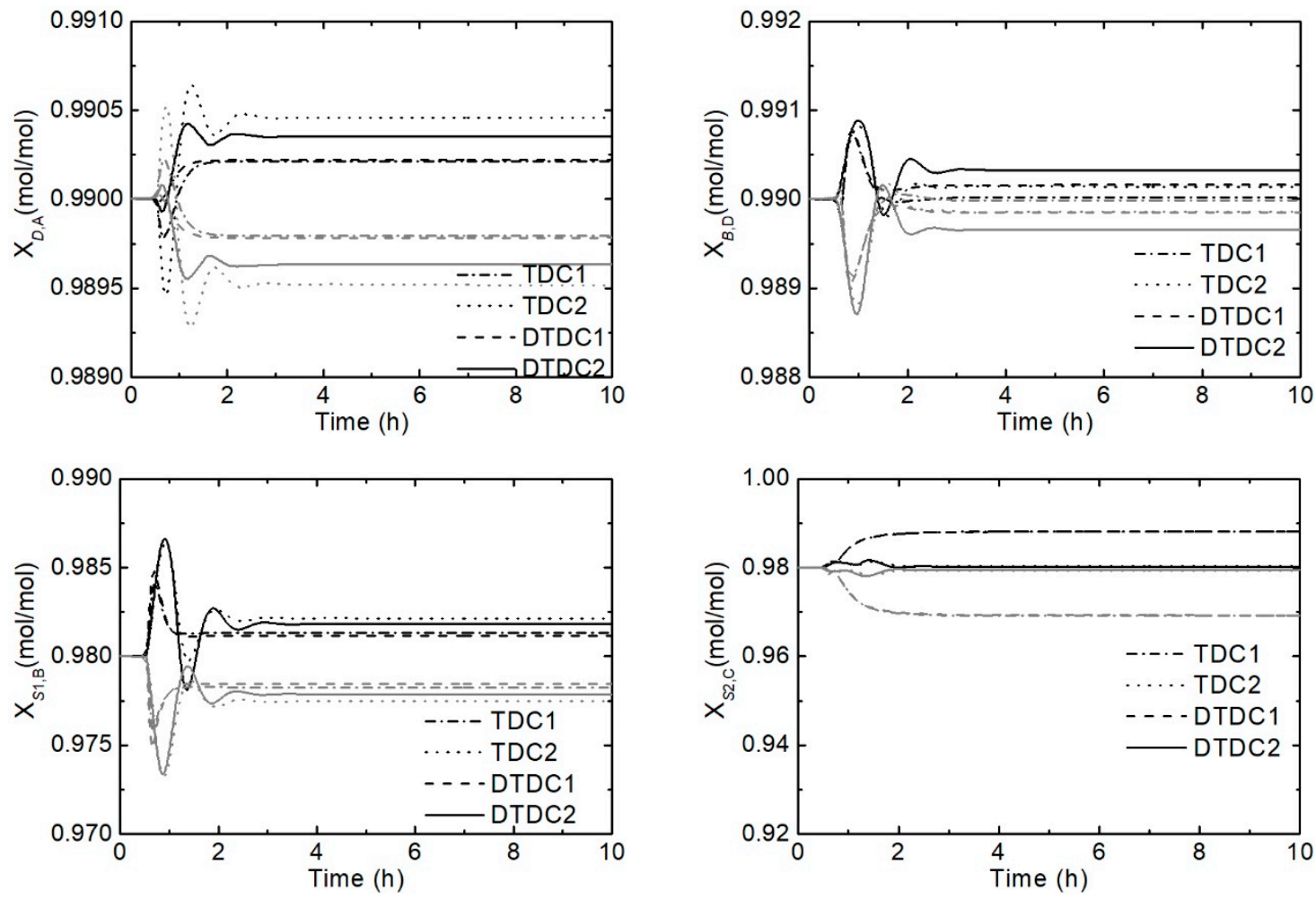

(b)

Figure 12. Cont. 

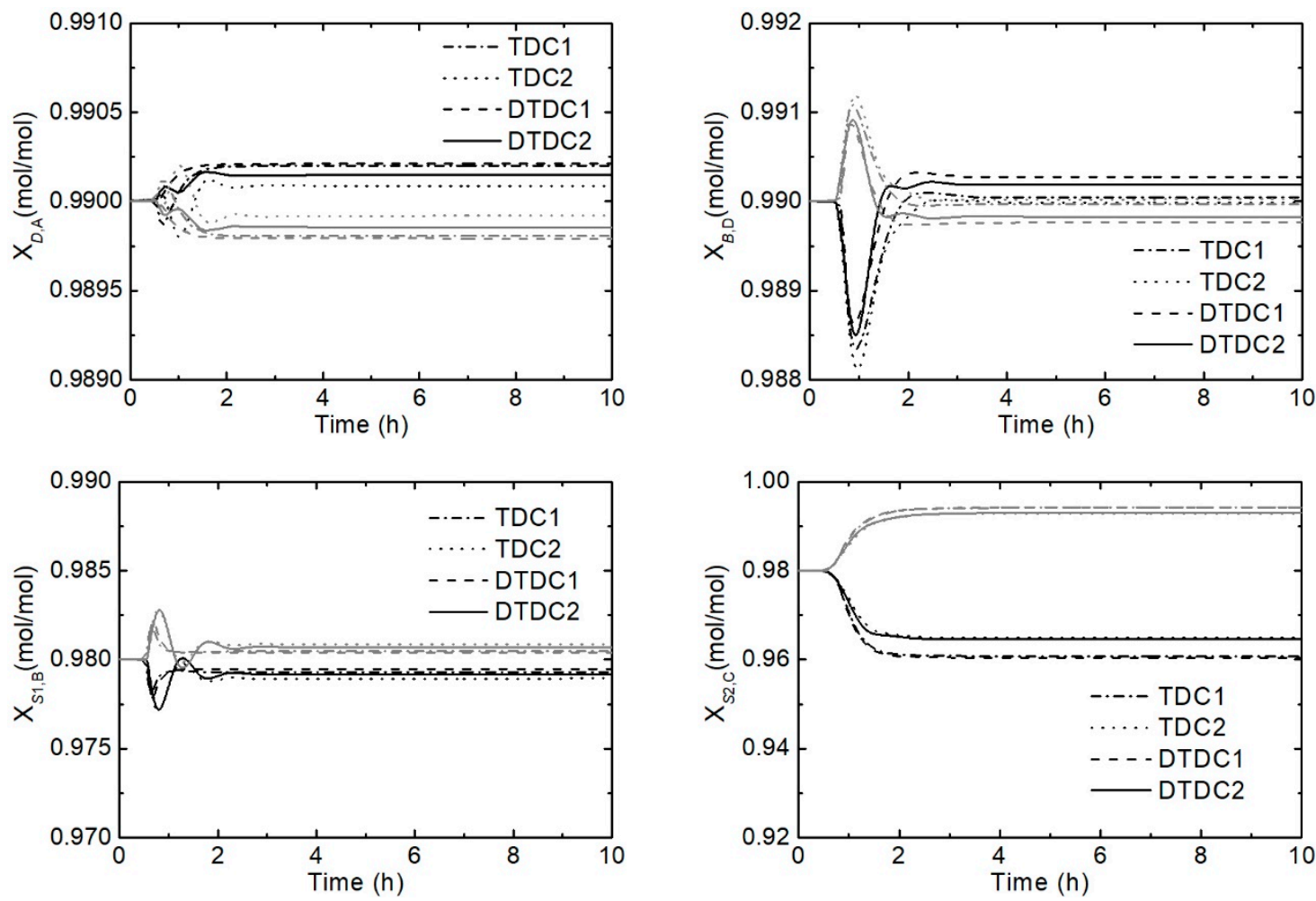

(c)
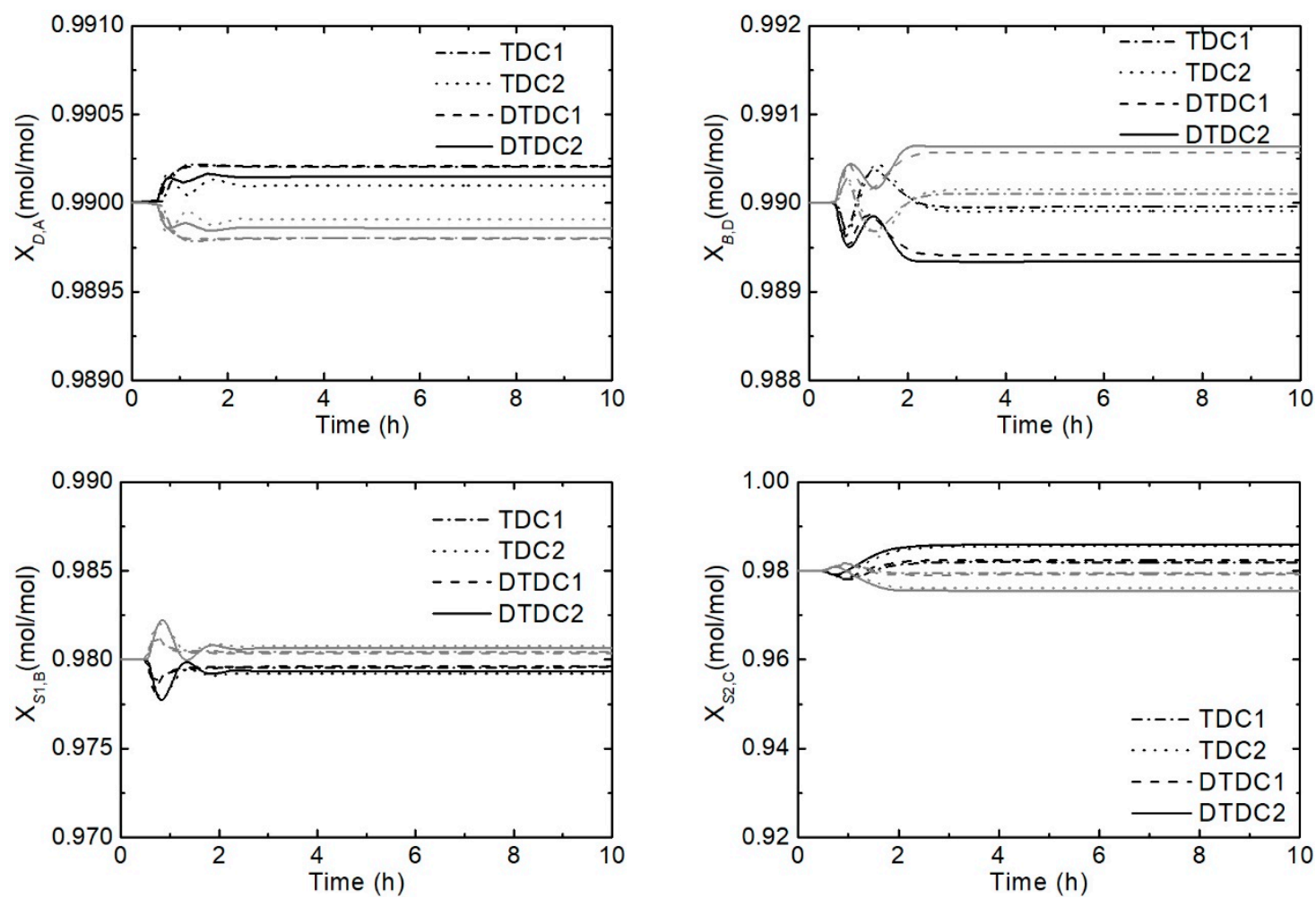

(d)

Figure 12. Cont. 

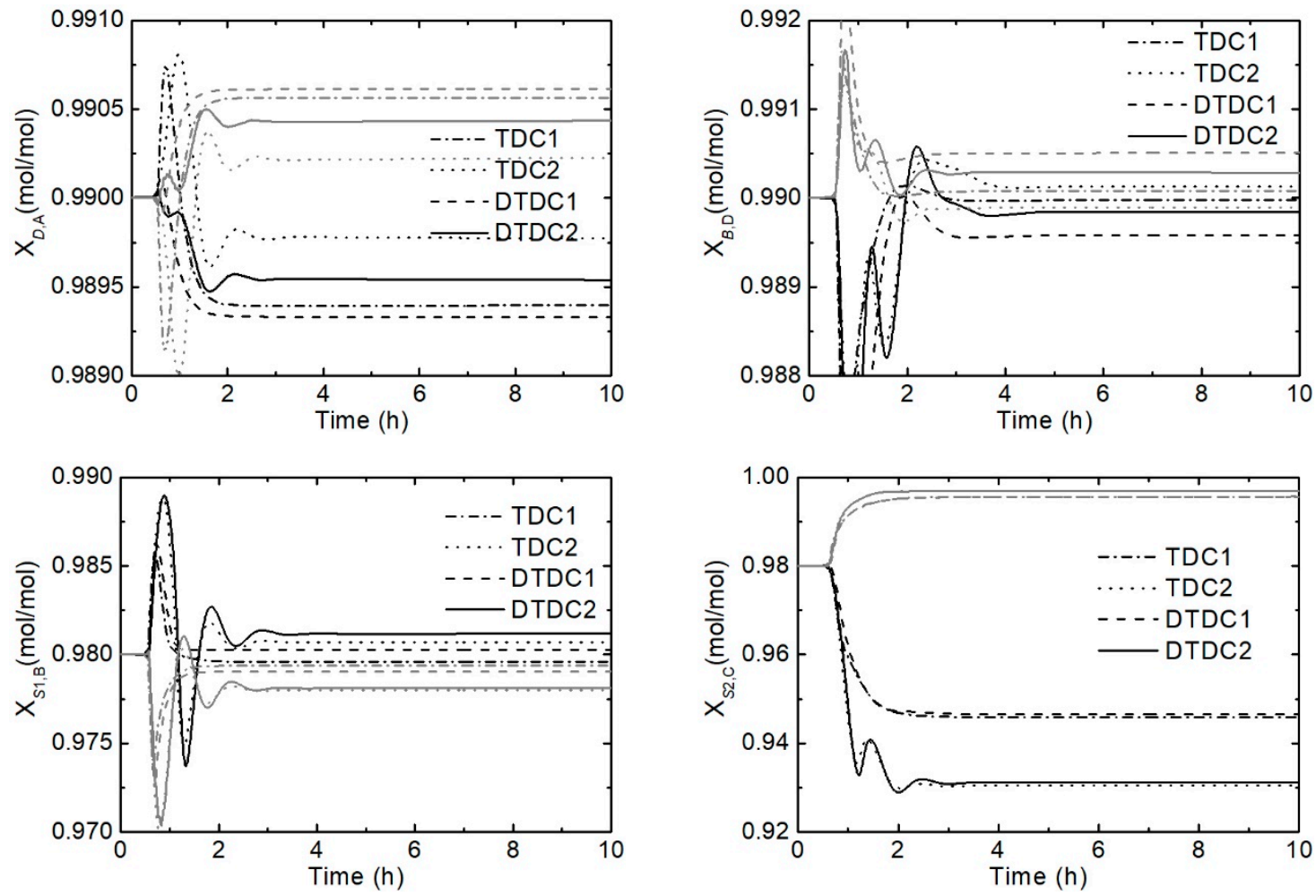

(e)

Figure 12. TDC versus DTDC: Dynamic results against $\pm 10 \%$ feed compositions and feed flow rate (F) disturbances: (a) A disturbances, (b) B disturbances, (c) C disturbances, (d) D disturbances, and (e) F disturbances.

\section{Conclusions}

Two TC structures, two TDC structures, and two DTDC structures were proposed for the four-product Kaibel DWC in this paper. The TC1, TDC1, and DTDC1 employed a liquid split in the control structures, while TC2, TDC2, and DTDC2 used a vapor split in the control structures. The feasibility of the proposed six control structures was verified with a wide variety of feed disturbances. We used one temperature control loop for each split for the stabilizing control layer [27]. The prefractionator carried out the $\mathrm{AB} / \mathrm{CD}$ split, so the prefractionator required one temperature controller, while the main column completed three sharp splits (including $\mathrm{A} / \mathrm{B}, \mathrm{B} / \mathrm{C}$, and $\mathrm{C} / \mathrm{D}$ splits), therefore it required three temperature controllers. In summary, at least four temperature controllers were needed. Temperature difference control was a better choice if the top and the bottom products were more important than the side products. Temperature control (TC1 and TC2) was better if the upper side product was important, while the control structure with $R_{\mathrm{L}}$ being the manipulated variable (TC1 and TDC1) was better if the lower side product was important. The dynamic performances of $S 2$ and $B$ were inferior to the dynamic performances of the top product and the upper side product because of the serious coupling in the stripping section. Control structures with active $R_{\mathrm{L}}$ were satisfactory if $S 2$ and $B$ were more important than $D$ and $S 1$. For the settling time, DTDC structures were best among the six control structures. The performances were all very smooth, and the settling times were very short. This paper proves that traditional PI control with only temperature sensors were able to deal with disturbances put into the complicated Kaibel DWC, which is an encouraging outcome that helps to promote the industrialization of the Kaibel DWC.

Author Contributions: Conceptualization, X.Q.; methodology, X.Q.; software, R.L.; validation, X.Q. and R.L.; formal analysis, X.Q. and R.L.; investigation, X.Q. and R.L.; resources, X.Q.; data curation, X.Q. and R.L.; 
writing—original draft preparation, X.Q. and R.L.; writing—review and editing, K.H., H.C., Y.Y., L.Z., and S.W.; supervision, K.H.; project administration, X.Q., K.H., H.C., Y.Y., and L.Z.

Funding: This research was funded by the National Nature Science Foundation of China (grant numbers: 21808007, 21878011, 21676011, 21576014), Open Foundation of State Key Laboratory of Chemical Engineering (grant number: SKL-ChE-18B01), China Postdoctoral Science Foundation (grant numbers: 2017M620587, 2019M650453), and Fundamental Research Funds for the Central Universities (grant numbers: ZY1837, ZY1930).

Conflicts of Interest: The authors declare no conflict of interest. The funders had no role in the design of the study; in the collection, analyses, or interpretation of data; in the writing of the manuscript, or in the decision to publish the results.

\section{References}

1. Kiss, A.A. Distillation technology-still young and full of breakthrough opportunities. J. Chem. Technol. Biotechnol. 2014, 89, 479-498. [CrossRef]

2. Dejanovic, I.; Matijasevic, L.; Olujic, Z. Dividing wall column-A breakthrough towards sustainable distilling. Chem. Eng. Process. 2010, 49, 559-580. [CrossRef]

3. Yildirim, O.; Kiss, A.A.; Kenig, E.Y. Dividing wall columns in chemical process industry: A review on current activities. Sep. Purif. Technol. 2011, 80, 403-417. [CrossRef]

4. Triantafyllou, C.; Smith, R. The design and optimisation of fully thermally coupled distillation columns: Process design. Chem. Eng. Res. Des. 1992, 70, 118-132.

5. Dejanovic, I.; Matijasevic, L.; Halvorsen, I.J.; Skogestad, S.; Jansen, H.; Kaibel, B.; Olujic, Z. Designing four-product dividing wall columns for separation of a multicomponent aromatics mixture. Chem. Eng. Res. Des. 2011, 89, 1155-1167. [CrossRef]

6. Dejanovic, I.; Halvorsen, I.J.; Skogestad, S.; Jansen, H.; Olujic, Z. Hydraulic design, technical challenges and comparison of alternative configurations of a four-product dividing wall column. Chem. Eng. Process. 2014, 84, 71-81. [CrossRef]

7. Kaibel, G. Distillation columns with vertical partitions. Chem. Eng. Technol. 1987, 10, 92-98. [CrossRef]

8. Ghadrdan, M.; Halvorsen, I.J.; Skogestad, S. Optimal operation of Kaibel distillation columns. Chem. Eng. Res. Des. 2011, 89, 1382-1391. [CrossRef]

9. Wolff, E.A.; Skogestad, S. Operation of integrated three-product (Petlyuk) distillation columns. Ind. Eng. Chem. Res. 1995, 34, 2094-2103. [CrossRef]

10. Wang, S.-J.; Wong, D.S.H. Controllability and energy efficiency of a high-purity divided wall column. Chem. Eng. Sci. 2007, 62, 1010-1025. [CrossRef]

11. Ling, H.; Luyben, W.L. New control structure for divided-wall columns. Ind. Eng. Chem. Res. 2009, 48, 6034-6049. [CrossRef]

12. Ling, H.; Luyben, W.L. Temperature control of the BTX divided-wall column. Ind. Eng. Chem. Res. 2010, 49, 189-203. [CrossRef]

13. Dwivedi, D.; Halvorsen, I.J.; Skogestad, S. Control structure selection for three-product Petlyuk (dividing-wall) column. Chem. Eng. Process. 2013, 64, 57-67. [CrossRef]

14. Dwivedi, D.; Halvorsen, I.J.; Skogestad, S. Control structure selection for four-product Petlyuk column. Chem. Eng. Process. 2013, 67, 49-59. [CrossRef]

15. Fan, G.; Jiang, W.; Qian, X. Comparison of stabilizing control structures for four-product Kaibel column. Chem. Eng. Res. Des. 2016, 109, 675-685. [CrossRef]

16. Qian, X.; Jia, S.; Skogestad, S.; Yuan, X. Control structure selection for four-product Kaibel column. Comput. Chem. Eng. 2016, 93, 372-381. [CrossRef]

17. Jia, S.; Qian, X.; Yuan, X. Optimal design for dividing wall column using support vector machine and particle swarm optimization. Chem. Eng. Res. Des. 2017, 125, 422-432. [CrossRef]

18. Jia, S.; Qian, X.; Yuan, X.; Skogestad, S. Control structure comparison for three-product Petlyuk column. Chin. J. Chem. Eng. 2018, 26, 1621-1630. [CrossRef]

19. Kiss, A.A.; Ignat, R.M. Innovative single step bioethanol dehydration in an extractive dividing-wall column. Sep. Purif. Technol. 2012, 98, 290-297. [CrossRef]

20. Kiss, A.A.; Suszwalak, D. Enhanced bioethanol dehydration by extractive and azeotropic distillation in dividing-wall columns. Sep. Purif. Technol. 2012, 86, 70-78. [CrossRef] 
21. Le, Q.-K.; Halvorsen, I.J.; Pajalic, O.; Skogestad, S. Dividing wall columns for heterogeneous azeotropic distillation. Chem. Eng. Res. Des. 2015, 99, 111-119. [CrossRef]

22. Luyben, W.L. Improved plantwide control structure for extractive divided-wall columns with vapor recompression. Chem. Eng. Res. Des. 2017, 123, 152-164. [CrossRef]

23. Staak, D.; Grutzner, T. Process integration by application of an extractive dividing-wall column: An industrial case study. Chem. Eng. Res. Des. 2017, 123, 120-129. [CrossRef]

24. Delgado-Delgado, R.; Hernandez, S.; Barroso-Munoz, F.O.; Segovia-Hernandez, J.G.; Castro-Montoya, A.J. From simulation studies to experimental tests in a reactive dividing wall distillation column. Chem. Eng. Res. Des. 2012, 90, 855-862. [CrossRef]

25. Feng, S.; Ye, Q.; Xia, H.; Li, R.; Suo, X. Integrating a vapor recompression heat pump into a lower partitioned reactive dividing-wall column for better energy-saving performance. Chem. Eng. Res. Des. 2017, 125, 204-213. [CrossRef]

26. Kiss, A.A.; Suszwalak, D. Innovative dimethyl ether synthesis in a reactive dividing-wall column. Comput. Chem. Eng. 2012, 38, 74-81. [CrossRef]

27. Skogestad, S. The Dos and Don'ts of Distillation Column Control. Chem. Eng. Res. Des. 2007, 85, 13-23. [CrossRef]

28. Luyben, W.L. Distillation Design and Control Using Aspen Simulation; John Wiley \& Sons: New York, NY, USA, 2013.

29. Luyben, W.L.; Chien, I.L. Design and Control of Distillation Systems for Separating Azeotropes; John Wiley \& Sons: New York, NY, USA, 2011.

30. Dwivedi, D.; Strandberg, J.P.; Halvorsen, I.J.; Skogestad, S. Steady state and dynamic operation of four-product dividing-wall (Kaibel) Columns: Experimental verification. Ind. Eng. Chem. Res. 2012, 51, 15696-15709. [CrossRef]

31. Dwivedi, D.; Strandberg, J.P.; Halvorsen, I.J.; Preisig, H.A.; Skogestad, S. Active vapor split control for dividing-wall columns. Ind. Eng. Chem. Res. 2012, 51, 15176-15183. [CrossRef]

(C) 2019 by the authors. Licensee MDPI, Basel, Switzerland. This article is an open access article distributed under the terms and conditions of the Creative Commons Attribution (CC BY) license (http://creativecommons.org/licenses/by/4.0/). 